\title{
THE INTRACEREBRAL MOUSE-PROTECTION TEST FOR PERTUSSIS VACCINES
}

\author{
BY J. O. IRWIN \\ Statistical Research Unit of the Medical Research Council, London School of Hygiene \\ and Tropical Medicine, Keppel Street, W.C.1
}

AND A. F. B. STANDFAST

The Lister Institute of Preventive Medicine, Elstree, Hertfordshire

CONTENTS

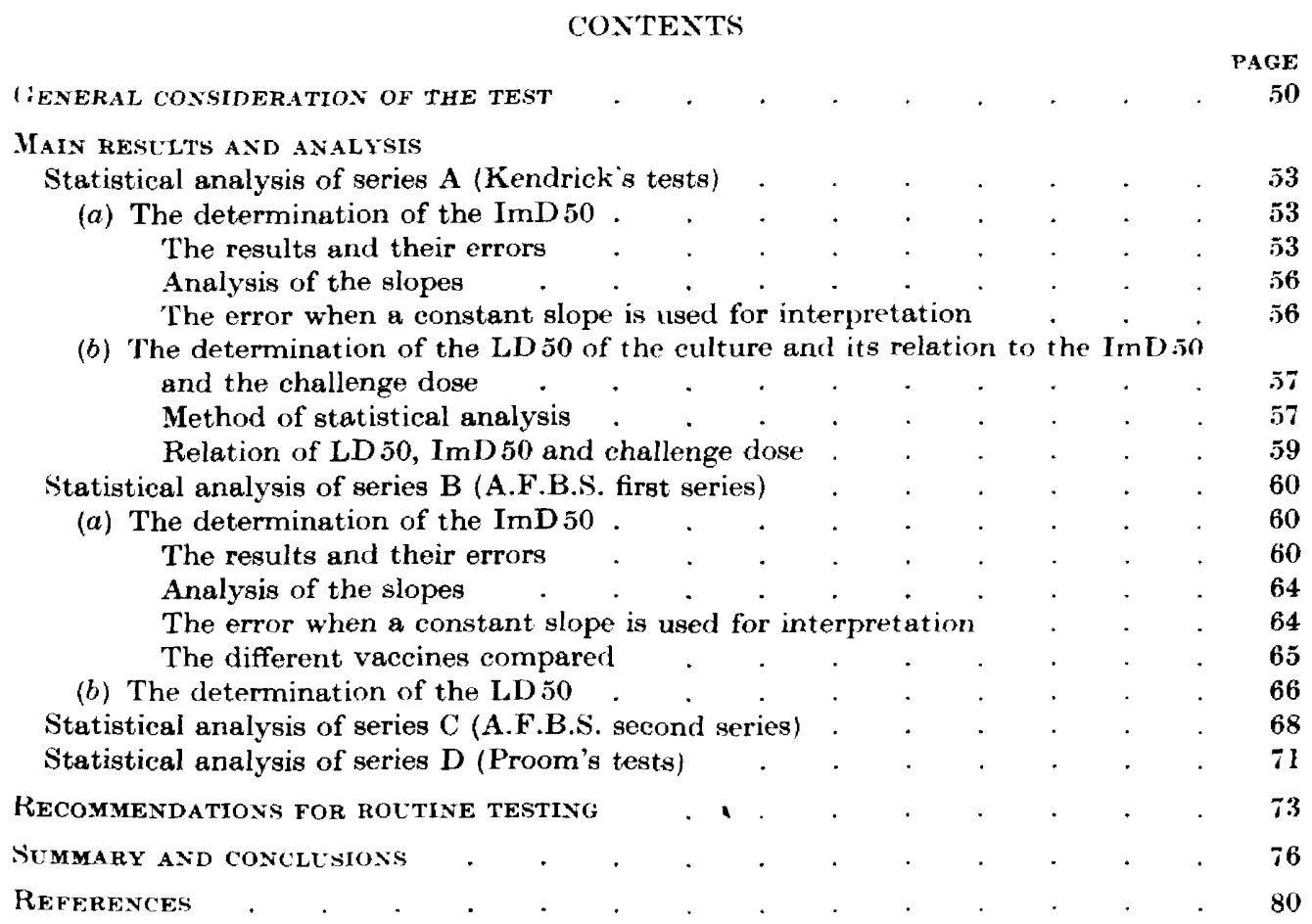

(GENERAL CONSIDERATION OF THE TEST

During the last eight years a great many determinations of the relative potencies of pertussis vaccines have been made by the mouse-protection test using the intracerebral route for challenge. Procedures for this test have been described in detail by Kendrick, Eldering, Dixon \& Misner (1947) and are given in Minimal Requirements (1948) and W.H.O. (1953). Briefly the method is as follows:

Selection of mice. White mice weighing 12-14 g., all of one sex, from the same known stock, are distributed at random into cages of fifteen mice. Three cages of fifteen mice are required for each antigen to be tested and a further four cages of unvaccinated controls are used for the titration of the challenge dose of viable Bordetella (Haemophilus) pertussis. 
Immunization of mice. A single dose of vaccine is given. Each antigen is usually diluted to contain 2000,400 and 80 million bacilli in $0.2 \mathrm{ml}$. saline and a group of fifteen mice injected intraperitoneally with each dose. The unvaccinated control mice are set aside at the same time and all the cages are kept together in the animal house. Period before challenge 10 days.

Challenge of mice. The challenge suspension of $B$. pertussis strain 18-323 is prepared from an 18-20 hr. culture on Bordet-Gengou medium by emulsifying a little of the growth in a $1 \%$ aqueous solution of Difco-Casamino acids (technical grade) so that $0.03 \mathrm{ml}$. contains 50,000 organisms by opacity, using the National Institute's of Health, Washington, U.S.A. (N.I.H.) ground-glass standard opacity tube. For the titration of the challenge dose three further dilutions to contain 5000,500 and 50 organisms in $0.03 \mathrm{ml}$. are usually prepared.

The mice are lightly anaesthetized with ether or ether-chloroform mixture and a dose of $0.03 \mathrm{ml}$. of a suitable dilution injected. Not more than $3 \mathrm{hr}$. is allowed to elapse between harvesting the challenge culture and injecting the last mouse.

Test period and calculation of results. The mice are observed for 14 days and a record kept of each death. Deaths occurring in the first $48 \mathrm{hr}$. after challenge are not included in the calculations. Mice which are paralysed on the 14th day, the last day of the assay, are considered as 'deaths'. Several methods are available for the calculation, in routine tests, of the ImD 50, the amount of vaccine which would protect $50 \%$ of mice, and the LD50, the amount of challenge suspension that would kill $50 \%$ of the control mice. The methods usually used are the ReedMuench (1938), the Worcester-Wilson (1943) or the Litchfield-Fertig (1941).

Our object was to discover whether the test was practicable and to determine its accuracy, and our conclusions in this respect are based in the main on four series of tests all of which had been carried out and analysed statistically by February 1950. Later tests provided further information but did not modify the essential conclusions reached. The four series were:

A. Six protocols containing in all twenty-six tests provided by Dr P. L. Kendrick (Michigan Dept. Health, U.S.A.)

B. A series of repeated tests carried out by one of us (A.F.B.S.) on seven vaccines. One of these was an American Standard, the remainder were of British manufacture.

C. Simultaneous tests carried out (A.F.B.S.) on vaccines, V1, V 2 and V3 (which were among those tested in B), twice a week over a period of 7 weeks.

D. A further fourteen simultaneous tests carried out by Mr H. Proom (Wellcome Research Laboratories. Beckenham) on vaccines V1, V 2 and V 3.

The details of the statistical analysis of these four series of tests are given below.

In carrying out any test of this type it is essential to keep the reagents and procedure as constant as possible, using mice obtained from the same closely bred stock. In spite of such 'standardization' the main difficulties of the mouse test are:

(a) the day-to-day variation in the infective potency of the challenge suspension; 
(b) the relatively restricted range of dosage of vaccine that can be given;

(c) the large day-to-day variation in ImD $50(50 \%$ immunizing dose) of the same vaccine;

(d) the large number of mice necessary to get a statistically significant result.

(a) In spite of every effort to standardize the challenge dose, its potency varies widely. Kendrick et al. (194i) reported that the LD50 (50\% lethal dose) of the challenge dose varied from 80 to 1870 organisms in ten laboratories collaborating in parallel assays, so that the challenge doses ranged from 20 to $500 \times \mathrm{LD} 50$. We have found a similar variation from day to day. Our results suggest that when the challenge dose is more than $200 \times \mathrm{LD} 50$, the $\operatorname{ImD} 50$ tends to be greater, but our data are too irregular to determine the precise form of the relationship. In any test, therefore, the challenge suspension may affect the variation described below in $(c)$.

(b) The range of dosage possible is restricted. The usual scheme is three doses, 2000,400 and 80 million: sometimes a fourth dose of 1000 million is added. 2000 million is about the maximum number of $B$. pertussis cells that can be given to a mouse without obvious toxic effects. Twice this dose is usually toxic for a proportion of the mice; at the other end of the scale 80 million may protect few if any of the mice so immunized, and doses below this are of little value, except on rare occasions when vaccines have, for reasons unknown, a very low $\operatorname{ImD} 50$ (see under $(c)$ ). The highest practicable dose is thus only 25 times the lowest, and, moreover, ImD 50's near either end of the range are less likely to be accurate than those in the middle; the demonstration of significant differences in ImD 50 is therefore not easy.

(c) Kendrick, Updyke \& Eldering (1949) reported that the ImD 50 in forty-five mouse-protection tests with vaccines prepared from culture 10-536, ranged from 50 to 1100 millions with a median of 230 , and they consider that these values for any vaccine might be so distributed. We have observed a somewhat similar range which must be regarded as the expected day-to-day variation. Unfortunately, Kendrick did not compare two vaccines at the same time, but in a series of comparative tests we made with two vaccines on fourteen occasions (Table 1), vaccine $V 3$ was better than vaccine $V 1$ ten times, and worse than $V 1$ four times, although when results of all these tests were combined vaccine $V 3$ was significantly better than V1. When the results obtained each day are inspected it will be seen that the ImD 50 of the two vaccines do not vary in parallel, and though in the first three tests vaccine $V 1$ was better than V3. this trend is not maintained in subsequent results.

This apparently random variation, coupled with the wide range of LD50 obtained with any vaccine and the restricted practicable dose range, means that any single result is far too dependent on chance to be reliable, even when a simple comparison 'better than' or 'worse than' is all that is required.

(d) Large numbers of mice used in multiple tests are therefore necessary to obtain significant results. It was decided to aim at being able to assert a significant difference (at the $5 \%$ level) when the estimated potency ratio was greater than 2 or less than $\frac{1}{2}$. The number of animals necessary for this purpose depends mainly on the slope of the dosage-response curve connecting the proportion of survivors 
with the logarithm of the dose. When the probit transformation is used these curves are linear. For series $A$, the slope was found to be $1.46 \pm 0.09$, for series $B$ $0.79 \pm 0.06$, for series $C 0.73$ and for series $D 0.93$. At the time when these tests were analysed, it was thought that series $A$ over-estimated the average accuracy obtainable.

Table 1. Comparison of ImD 50's of two vaccines V 1 and V 3 tested together on fourteen occasions

\begin{tabular}{ccc} 
& \multicolumn{2}{c}{ ImD50 in millions } \\
\cline { 2 - 3 } Date of test & 210 & Vaccine V 1 \\
6. xii. 48 & 1300 & 150 \\
7. xii. 48 & 1400 & 650 \\
13. xii. 48 & 400 & 850 \\
14. xii. 48 & 510 & 2700 \\
20. xii. 48 & 400 & 900 \\
21. xii. 48 & 630 & 2100 \\
28. xii. 48 & 710 & 950 \\
1. i. 49 & 400 & 1300 \\
3. i. 49 & 2000 & 1300 \\
4. i. 49 & 1300 & 3300 \\
10. i. 49 & $\infty$ & 1400 \\
11. i. 49 & 830 & 2000 \\
17. i. 49 & 240 & 2200 \\
2 s. i. 49 & & 750
\end{tabular}

MAIN RESULTS AND ANALYSIS

Statistical Axalysis of Series A (Kexdrick's tests)

(a) The determination of the $\operatorname{ImD} 50$

Dr Pearl L. Kendrick provided protocols of six experiments which were analysed statistically. The six experiments contained in all twenty-six tests, for each of which she had already estimated the ImD 50, by the Reed-Muench methodessentially a form of Behrens's method. The individual tests were, with one exception, carried out with three immunizing doses and fifteen animals to a dose; the exception was test $\mathrm{C} 224$ in which there were four doses. Consecutive doses were in the ratio of 5 to 1 in three $(164,184,190)$ and 4 to 1 in two $(186,187)$. In experiment 176 the same antigen was used throughout, but the ratio between consecutive doses was changed from one test to another.

The results and their errors. The Reed-Muench method is a rapid method of estimation which in itself provides no adequate estimate of error. The object of the statistical analysis presented here is to make the best possible estimates of the ImD 50, to determine fiducial limits for their error and to examine the constancy of the relation between dose and response. All the results are shown in Table 2.

Each test was first treated as a self-contained test. The probit (or normal equivalent deviation) corresponding to the percentage of survivors on any dose was assumed to be a linear function of the logarithm of the dose and the best fitting straight lines were obtained. From these the values of the $\operatorname{ImD} 50$ were 


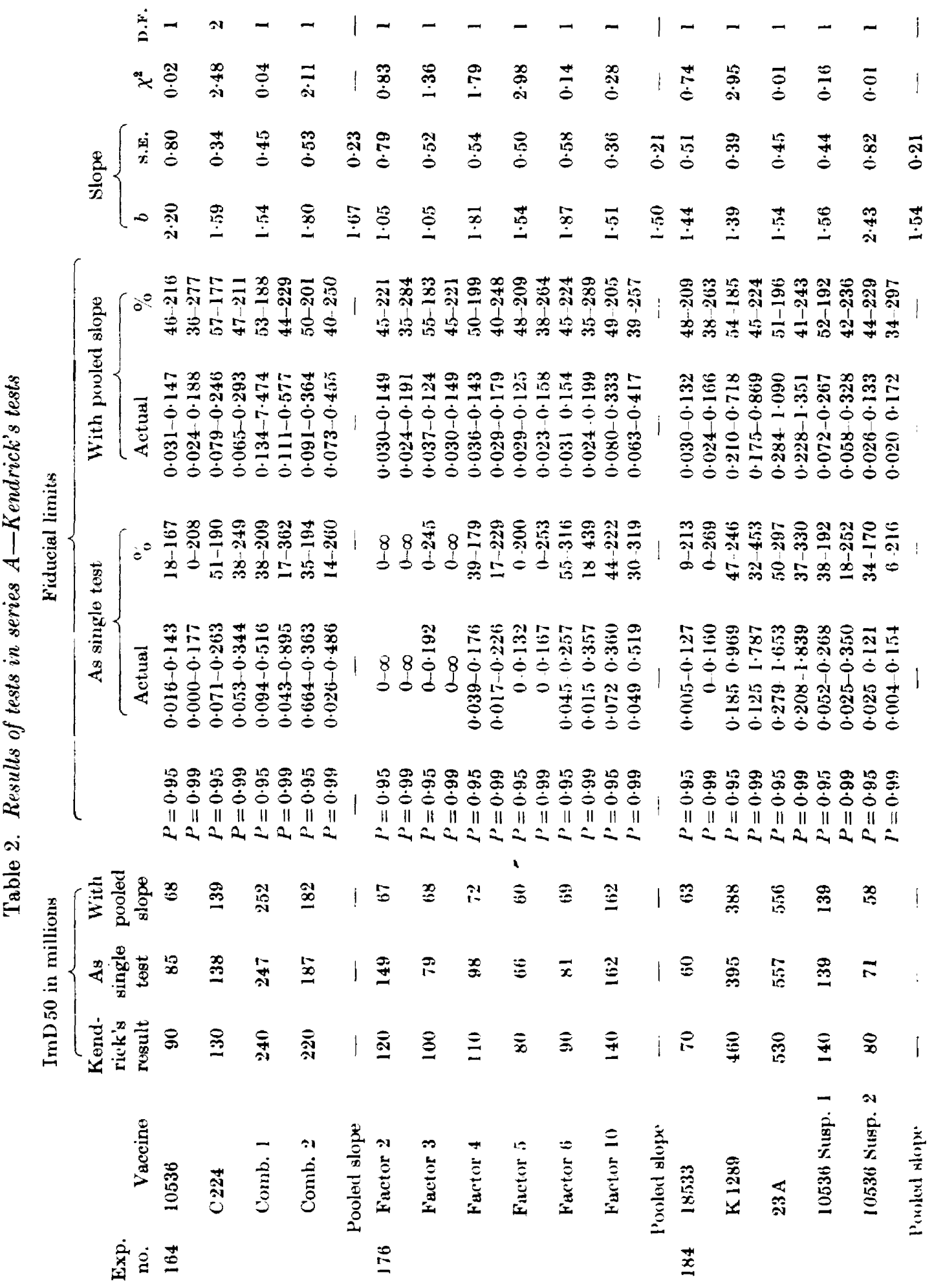




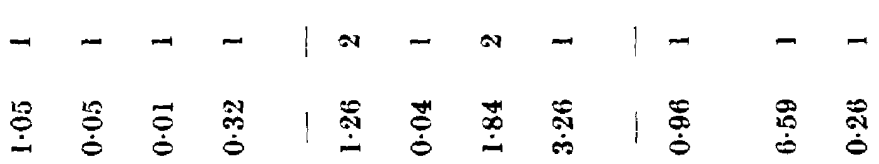

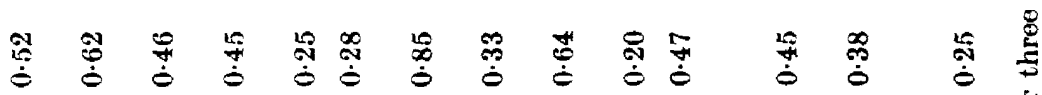

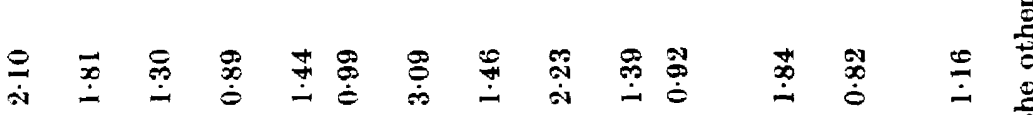

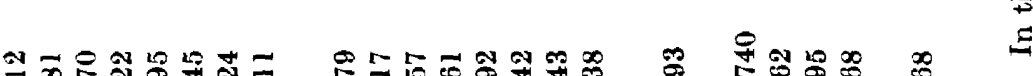

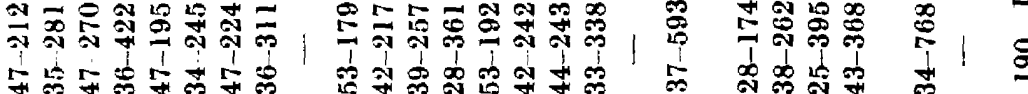

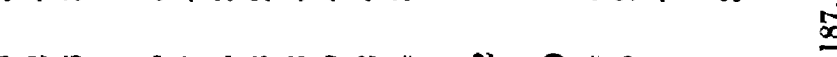

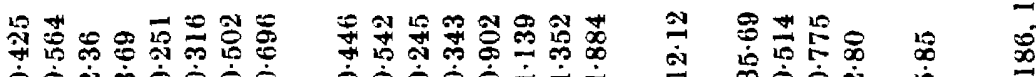

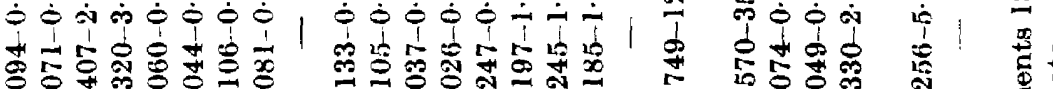

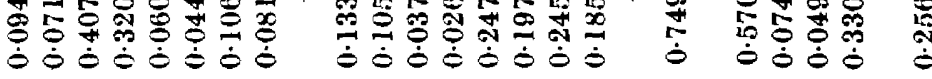


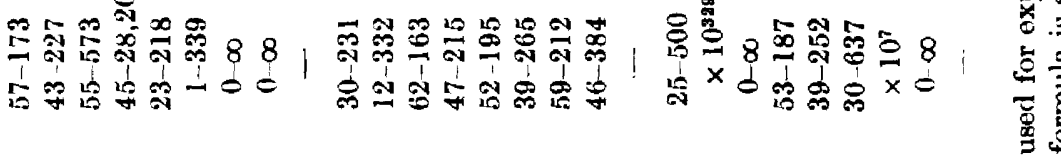

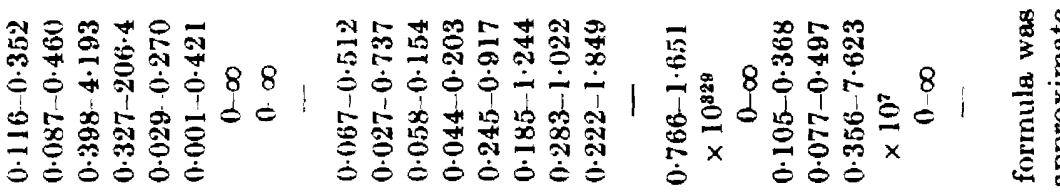

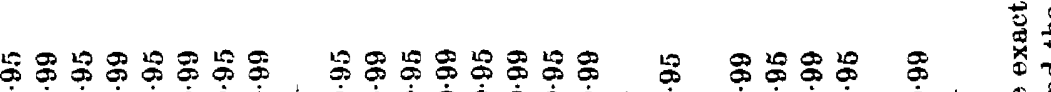
OII

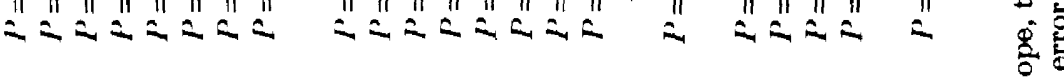

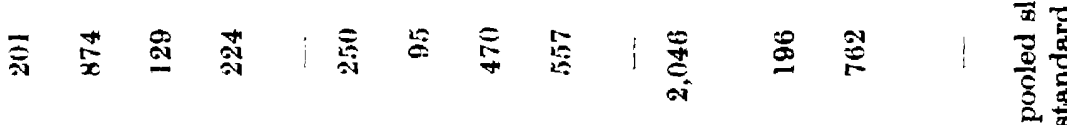

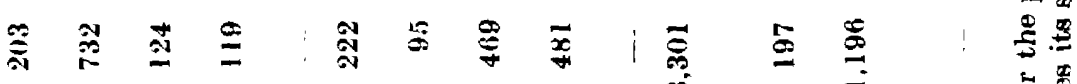

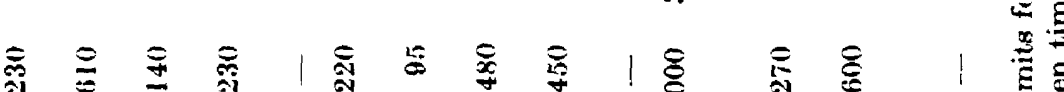

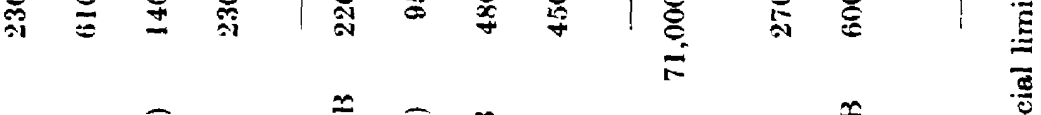

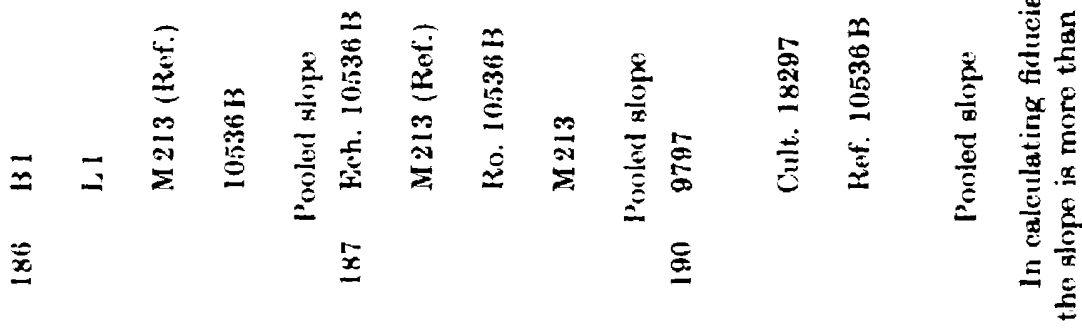


estimated and the fiducial limits for $P=0.95$ and $P=0.99$ were calculated. The estimates of slope made from each separate test inevitably have very large sampling errors, and a large part of the errors of the estimates of the $\operatorname{ImD} 50$ is due to the uncertainty of the slope. In a few cases (six tests out of twenty-six) the slope did not differ significantly from zero, in which case the fiducial limits become $0-\infty$. This means that the test, regarded as a self-contained test, provides no evidence of increasing protection with increasing dose and that consequently no valid estimate of the $\operatorname{ImD} 50$ can be made from it.

No significant departures from linearity and no significant differences in slope from test to test within the same experiment were found. Accordingly, a pooled estimate of slope was next made for each experiment and the ImD 50's and their fiducial limits of error were recalculated, using the pooled estimate.

Columns (3), (4) and (5) of Table 6 give (i) Kendrick's estimate, (ii) the estimate when each test is treated as a single self-contained test, (iii) the estimate when the pooled slope from each experiment is used. Columns (6) and (8) give the fiducial limits of error for the estimates (ii) and (iii), and in columns (7) and (9) these are expressed as percentages of the corresponding estimate. When a pooled slope is used the fiducial limits are very considerably narrower and approximate to the real limits of error of the test when the effect of uncertainty of slope is eliminated. Omitting experiment 190 for which the slope is less than 5 times its standard error, the average fiducial limits are close to $50-200 \%$ at $P=0.95(49-209 \%$ without experiment 190 and $48-232 \%$ with experiment 190). Thus the true value can be taken to be between half and double the estimate.

Analysis of the slopes. No significant differences between experiments were found in the pooled slopes. The average overall slope is 1.46 with a standard error of $0 \cdot 09$, and the data as a whole are consistent with this constant value.

Table 3 gives an analysis of variance of the slopes.

It is worth noting that the expected values of the mean squares in Table 3 are unity, on the assumption that response is linearly related to the logarithm of the dose, and that the animals form a homogeneous group in respect to their reactions to the antigen. The mean square between experiments is somewhat below its expected value but not significantly so. The other two mean squares are remarkably close to their expected values. Since the mean square between experiments is not significantly subnormal no special explanation is called for, but the result does suggest that the experiments selected in these protocols are a little better than the usual.

The error when a constant slope is used for interpretation. The data are consistent with the hypothesis that the true slope is constant with a value close to $1 \cdot 5$. The actual estimate obtained is $1 \cdot 46 \pm 0 \cdot 09$. The average value of the sum of the weights $\Sigma n w$ is close to $20(19 \cdot 60)$. These values are used below to calculate the average errors of a single determination of the $\operatorname{ImD50}$ with forty-five animals and of the potency ratio of a test vaccine to a reference vaccine with forty-five animals on each preparation.

For a single determination these errors depend, although only slightly, on the values of $5-\bar{y}$, the deviation of the average probit response from 5 and, for the 
determination of a potency ratio, on $\bar{y}_{2}-\bar{y}_{1}$, the difference between the meanprobit responses to the test and reference vaccine. The results are shown in Table 4.

Table 3. Analysis of variance of slopes-series $A$

\begin{tabular}{|c|c|c|c|}
\hline & Sum of squares & D.F. & Mean square \\
\hline Between experiments & $2 \cdot 6387$ & 5 & 0.5278 \\
\hline Within experiments: Between tests & I9. 1364 & 20 & 0.9568 \\
\hline Within tests & $31 \cdot 5252$ & 29 & $1 \cdot 0871$ \\
\hline
\end{tabular}

Table 4. Fiducial limits of error-series $A$

\begin{tabular}{|c|c|c|c|c|}
\hline \multirow[b]{2}{*}{$\begin{array}{c}\bar{y}-\bar{y} \text { or } \\
\bar{y}_{2}-\bar{y}_{1}\end{array}$} & \multicolumn{2}{|c|}{$\begin{array}{c}\text { Single determination of } \\
\text { the } \operatorname{ImD} 50\end{array}$} & \multicolumn{2}{|c|}{$\begin{array}{l}\text { Potency ratio--test } \\
\text { against standard }\end{array}$} \\
\hline & $\begin{array}{c}P=0.95 \\
\left(\begin{array}{c}0 \\
.0\end{array}\right)\end{array}$ & $\begin{array}{c}P=0.99 \\
\left({ }_{0}^{o}\right)\end{array}$ & $\begin{array}{c}P=0.95 \\
\left({ }_{0}^{0}\right)\end{array}$ & $\begin{array}{c}P=0.99 \\
\left({ }_{0}^{0}\right)\end{array}$ \\
\hline 0 & $50-201$ & $40-251$ & $3 \bar{\imath}-269$ & $27-368$ \\
\hline 0.25 & $50-202$ & $40-251$ & $37-269$ & $27-369$ \\
\hline 0.50 & $49-203$ & $40-253$ & $37-271$ & $27-372$ \\
\hline 0.75 & $48-204$ & $39-256$ & $36-275$ & $26-377$ \\
\hline 1.00 & $48-207$ & $39-260$ & $36-279$ & $26-385$ \\
\hline
\end{tabular}

(b) The determination of the LD50 of the culture and its relation to the ImD 50 and the challenge dose

Method of statistical analysis. One determination was made in each experiment with three or four doses at five-fold intervals. The values of LD 50 were estimated by finding the best-fitting straight line connecting the probit, corresponding to the mortality observed, with the logarithm of the dose. Fiducial limits corresponding to $P=0.95$ and $P=0.99$ were then obtained. In fact, the statistical method used was the same as that for the values of $\operatorname{ImD} 50$.

With the possible exception of experiment 186 no significant differences in slope from experiment to experiment were found. The results could therefore be interpreted with regard to a pooled slope. This average slope was $1 \cdot 11$ including experiment 186 and 1.06 excluding it; there was therefore no point in the exclusion and the seven experiments could be regarded as homogeneous in slope. Table 5 gives the results and their errors. The estimates of the LD50 by the three methods (i) Kendrick's own estimate by the Reed-Muench method, (ii) interpretation as a single test, (iii) interpretation with respect to a pooled slope, do not differ greatly compared with differences due to the sampling variation of the animals. The latter are of course large. When interpreted with regard to the pooled slope the average fiducial limits for a single determination from forty-five animals are $40-250 \%$.

The $\chi^{2}$ values show that there were no significant differences of the probit-logdose relationship from linearity.

The analysis of variance of slopes is shown in Table 6. The theoretical expectation is unity for each mean square, and neither diverges significantly from unity at the $5 \%$ level of significance. If there is any heterogeneity in slope it is due to the value $2 \cdot 47$ for experiment 186 . 


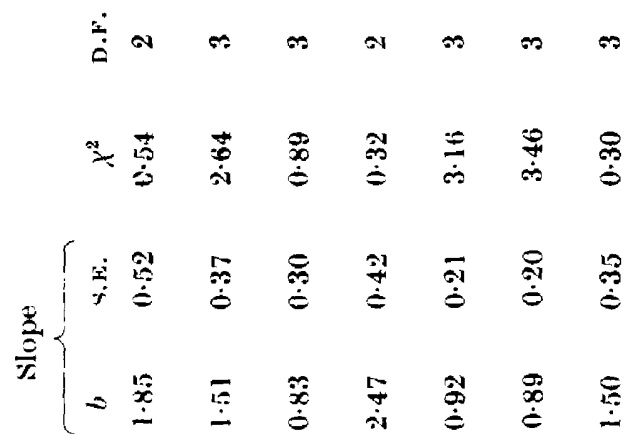

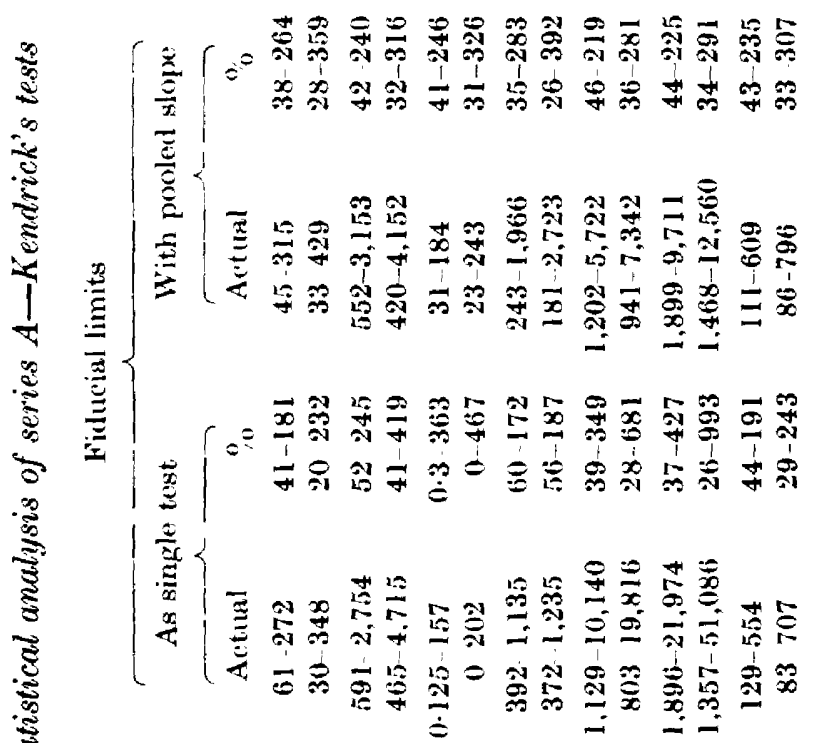

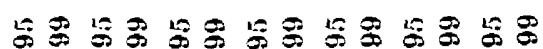
II

s. $\angle 2=22=22=22=2$

$\frac{0}{0}$

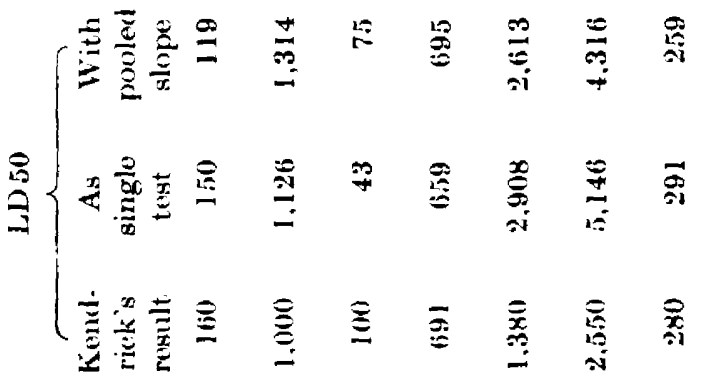

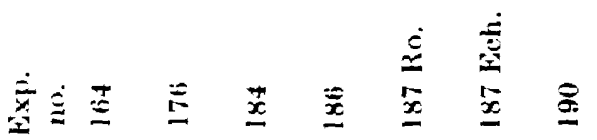


Table 6. Analysis of variance of slopes

$\left.\begin{array}{lrrc} & \begin{array}{c}\text { Sum of } \\ \text { squares }\end{array} & \text { D.F. } & \text { Mean square } \\ \text { Between slopes } & 12 \cdot 382 & 6 & 2 \cdot 064 \\ \text { Residual } & 11.308 & 12 & 0.942\end{array}\right\}$ V.R. 2.19

Relation of LD50, ImD 50 and challenge dose. The logarithms of the LD50 and their standard errors are shown in Table 7.

\begin{tabular}{|c|c|c|c|c|}
\hline \multirow[b]{2}{*}{ Experiment } & \multicolumn{2}{|c|}{ from series $A$} & & \multirow{2}{*}{$\begin{array}{c}\text { Fiducial } \\
\text { limits } \\
(P=0.95)\end{array}$} \\
\hline & LD 50 & $\log \mathrm{LD} 50$ & s.e. & \\
\hline 176 & 1314 & $3 \cdot 119$ & 0.194 & \\
\hline 164 & 119 & $2 \cdot 077$ & 0.225 & \\
\hline 184 & 75 & 1.873 & $0 \cdot 199$ & \\
\hline 190 & 259 & $2 \cdot 414$ & 0.189 & \\
\hline 186 & 695 & $2 \cdot 842$ & $0 \cdot 230$ & \\
\hline 187 Ro. & 2613 & $3 \cdot 417$ & $0 \cdot 174$ & \\
\hline 187 Ech. & 4316 & $3 \cdot 635$ & $0 \cdot 180$ & \\
\hline \multicolumn{5}{|l|}{ Mean } \\
\hline $164,184,190$ & 136 & $2 \cdot 134$ & $0 \cdot 116$ & $18-228$ \\
\hline 186, 187, Ro. and Ech. & 2330 & $3 \cdot 368$ & 0.110 & $1418-3828$ \\
\hline
\end{tabular}

Experiment 176 was one on antigen 16945 with different dose intervals in the different tests, and we are not further concerned with it here. The remaining values of the LD 50 fall into groups within which there are no significant differences. The mean value for the first group is $\mathbf{1 3 6}$ and for the second 2330 , which, taking the error into account, may be called 150 and 2500 with as much accuracy as is justifiable.

It is interesting to compare the values of the ImD 50 with those of the LD 50 and the challenge doses. There are in all seven tests with antigen 10536 , for which we may construct Table 8 . The estimates of the $\operatorname{ImD50}$ in the first group do not differ

Table 8. Comparison of ImD50 and LD50 of challenge dose in series $A$

$\begin{array}{llcccc}\text { Exp. } & \text { Antigen } & \begin{array}{c}\text { ImD 50 in } \\ \text { millions }\end{array} & \begin{array}{c}\text { Challenge } \\ \text { dose }\end{array} & \text { LD 50 } & R=\frac{\text { C.D. }}{\text { LD 50 }} \\ 164 & \text { Ref. } & 68 & 40,000 & 150 & 270 \\ 184 & \text { Susp. 1 } & 139 & 40,000 & 150 & 270 \\ 184 & \text { Susp. 2 } & 58 & 40,000 & 150 & 270 \\ 186 & \text { B } & 224 & 40,000 & 2500 & 16 \\ 187 \text { Ro. } & \text { B } & 250 & 50,000 & 2500 & 20 \\ 187 \text { Ech. } & \text { B } & 470 & 50,000 & 2500 & 20 \\ 190 & \text { B } & 762 & 50,000 & 150 & 330\end{array}$

significantly, nor do those in the second group. Assuming that we can regard the two groups as referring to two different antigens, or two different batches of the 
same antigen, it is clear that the ImD 50's in the first group are comparable. Both the challenge dose and the ratios $R$ are the same for all three. The value of $R$ for experiment 190 is about the same as for those in the first group; the inference from this is that the second antigen is really weaker than the first. There is no doubt about this however we regard the data. In the second group while the values of the $\operatorname{ImD} 50$ do not differ significantly the $R$ ratio is greater for experiment 190 than for the other three. It is possible, however, that the differences between the ImD 50's may be real. In this case the result supports the view that the ImD 50 increases as the ratio of challenge dose to LD 50 increases. But there is not enough evidence in these data to prove that the $\operatorname{ImD} 50$ is directly proportional to $R$.

When an antigen is always tested by means of a comparison with a standard, the same challenge dose of the same culture being used for both, the difficulty probably disappears, because one would expect the potency ratio of test to standard to be independent of $R$. In the data analysed there were no significant changes of slope although the values of $R$ varied, and this is a hopeful sign.

\section{Statistical Axalysis of Series B \\ (A.F.B.S. FIRST SERIES) \\ (a) The determination of the $\operatorname{ImD} 50$}

The data consisted of repeated tests on seven vaccines. Each vaccine was tested at three dose levels at five-fold intervals with fifteen mice on a dose. The LD 50 in the controls was determined from four doses at 10 -fold intervals with fifteen mice on a dose. The results have been evaluated (i) by the Reed-Muench method and (ii) by the probit method, so as to determine the maximum-likelihood estimates and fiducial limits for their error. All the results are shown in Table 9.

The results and their errors. Each test was first treated as a self-contained test. The probit (or normal equivalent deviation) corresponding to the percentage of survivors on any dose was assumed to be a linear function of the dose and the best. fitting straight line was obtained. From these values the $\operatorname{ImD} 50$ 's were estimated and the fiducial limits for $P=0.95$ and $P=0.99$ were calculated. As in Kendrick's results, and as is indeed inevitable, the estimates of slope made from each separate test have very large sampling errors, and a large part of the errors of the estimates of $\operatorname{ImD} 50$ is due to the uncertainty of slope. Three tests (those on V 1 and $V 2$ on 6 August 1948 and that on $V 1$ on 21 September 1948) failed because there were no survivors except at the highest dose. In about half the tests (twenty at $P=0.95$ and twenty-six at $P=0.99$ ) the slope did not differ significantly from zero, in which case the fiducial limits become $0-\infty$. This means that the test regarded as a selfcontained test, provides no evidence of increased protection with increasing dose and that consequently no valid estimate of the $\operatorname{ImD50}$ can be made from it.

With two possible exceptions no significant departures from linearity and no significant differences in slope were found. Accordingly, an overall pooled estimate of slope was made and the ImD 50's and their fiducial limits of error were recalculated using the pooled estimate, which proved to be 0.788 with a standard error of $0 \cdot 064$. 


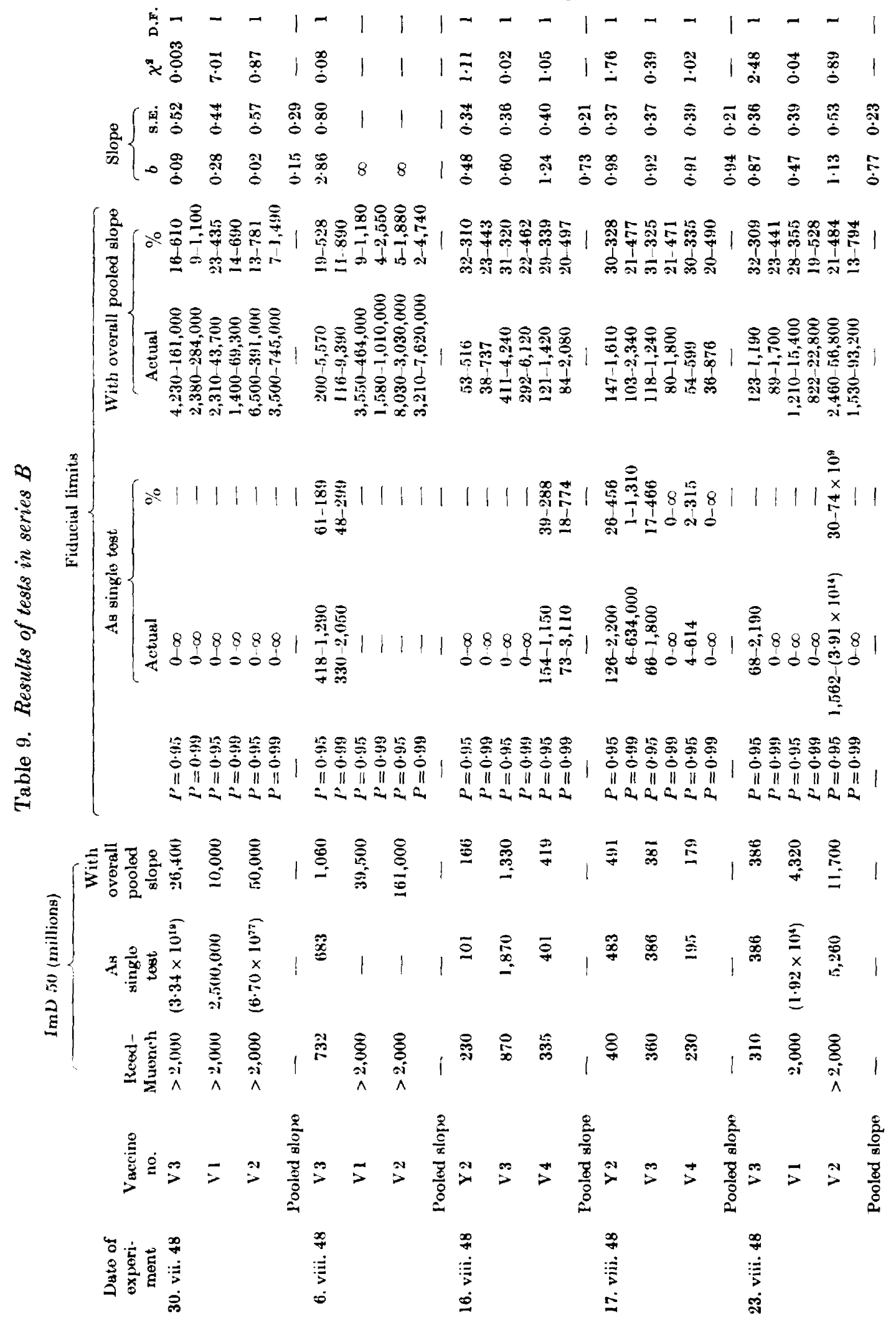




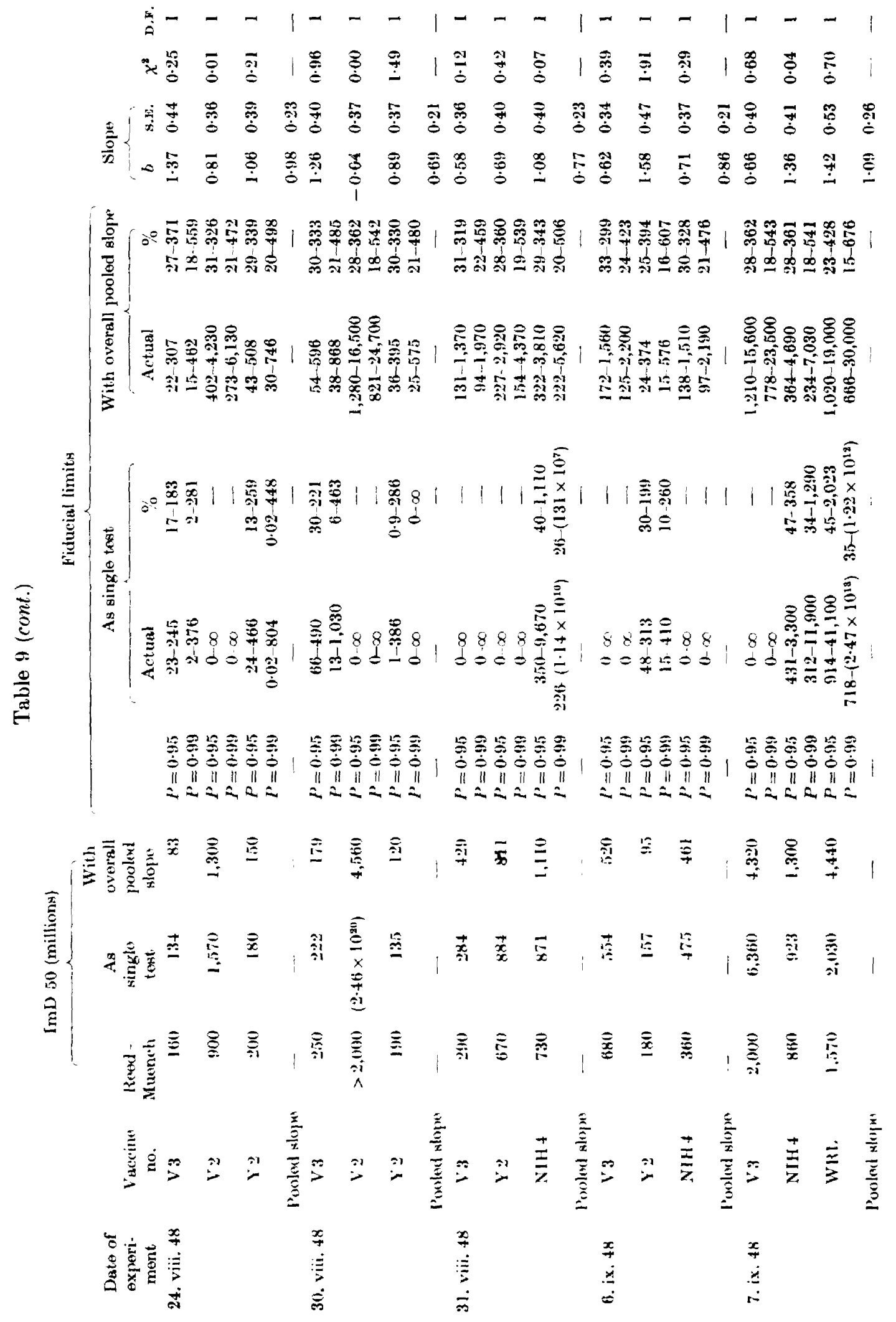




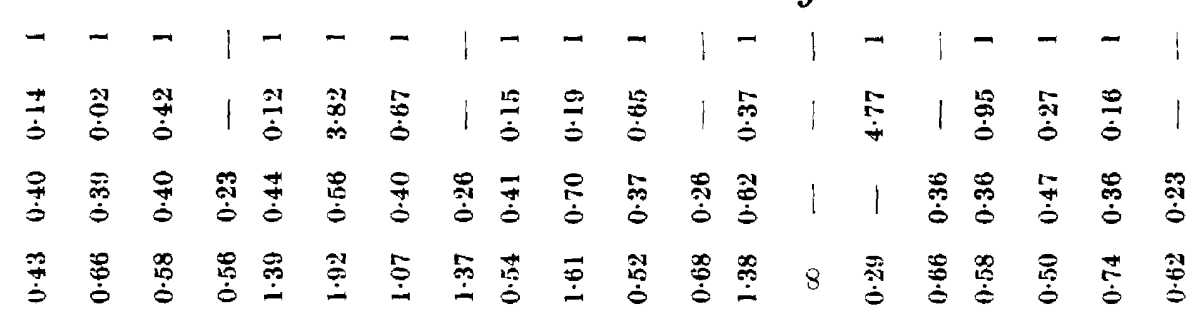

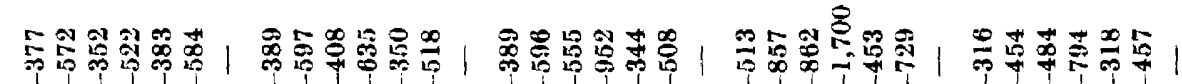

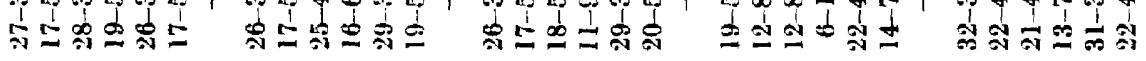

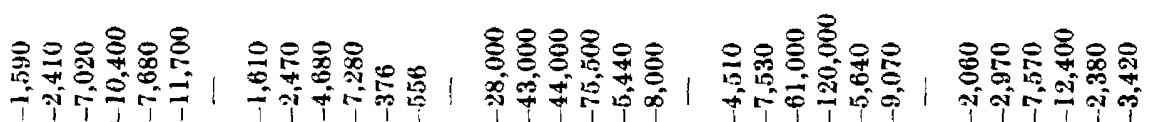

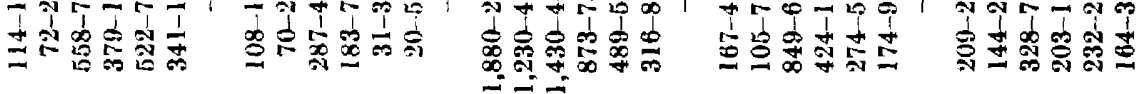

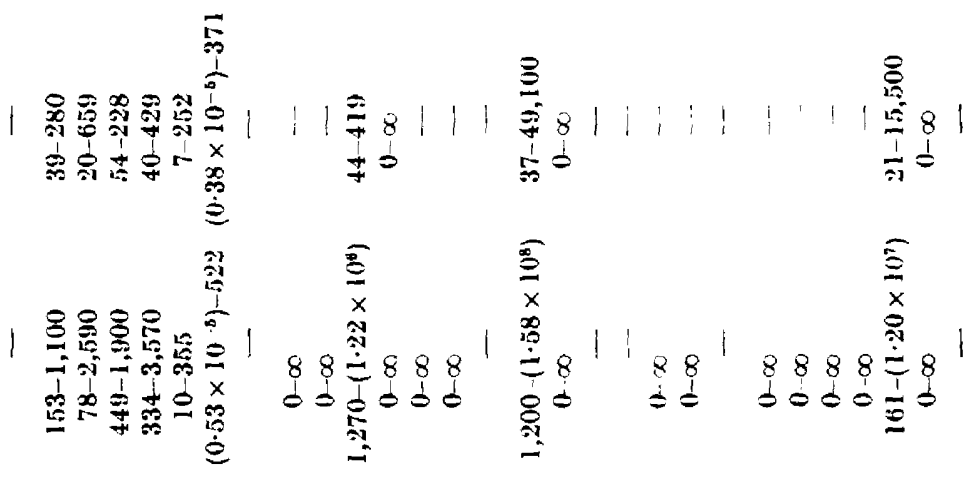

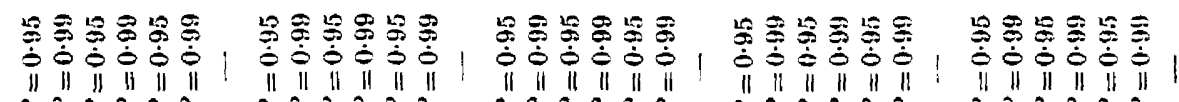

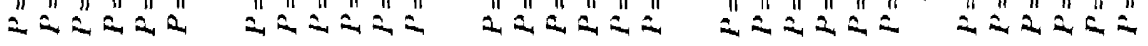

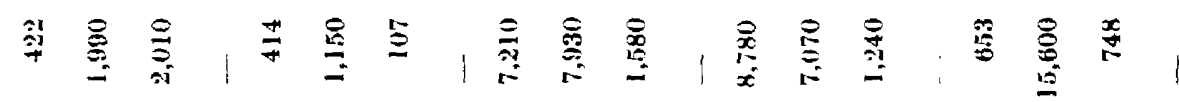

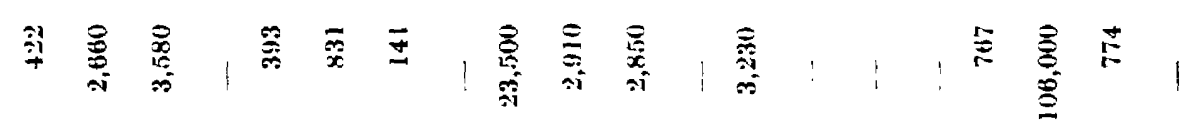

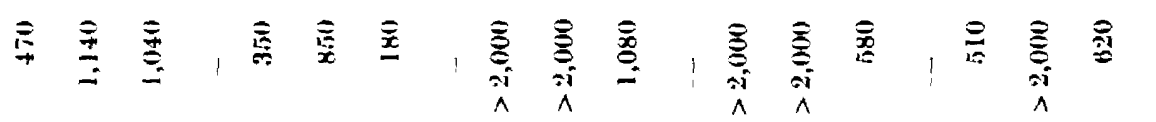

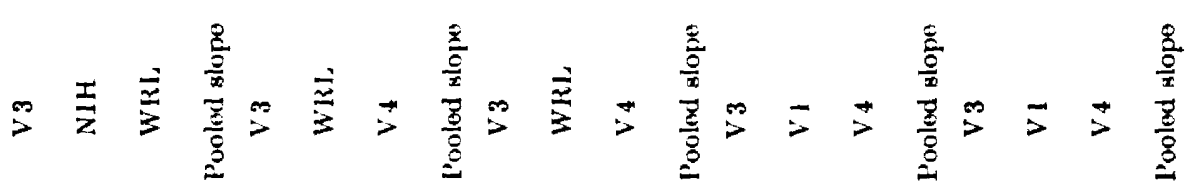

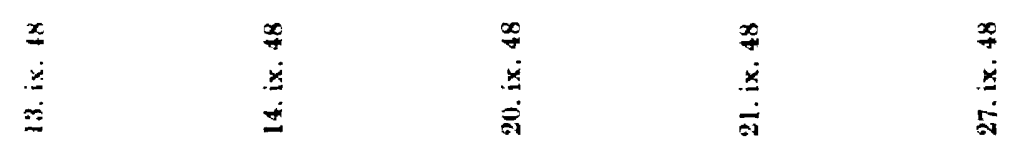


Columns (3), (4) and (5) of Table 13 give (i) the Reed-Muench estimate, (ii) the estimate when each test is treated as a single self-contained test, (iii) the estimate when the pooled slope is used. Columns (6) and (8) give the fiducial limits of error from the estimates (ii) and (iii), and in columns (7) and (9) these are expressed as percentages of the corresponding estimates. When a pooled slope is used the fiducial limits are very considerably narrower, on the average, and approximate to the real limits of error of the test when the effect of uncertainty of slope is eliminated. The average fiducial limits are $26-450 \%$ at $P=0.95$ or $27-365 \%$, omitting the three tests which 'failed'. The corresponding limits in those of Kendrick's tests which we examined were 49-209\%. The Kendrick tests examined were therefore decidedly more accurate, due to a slope which is almost double the slope obtained here.

The Reed-Muench method is clearly accurate enough for purposes of routine estimation, since errors due to the method of estimation are small compared with those due to the sampling variation of the mice. The Reed-Muench method, however, provided no valid estimate of error.

Analysis of the slopes. No significant differences between tests were found in the slopes. The average overall slope is 0.788 with a standard error of 0.064 and the data as a whole are consistent with this constant value. Table 10 gives the analysis of variance of the slopes.

Table 10. Analysis of variance of slopes in series $B$

\begin{tabular}{|c|c|c|c|}
\hline & $\begin{array}{l}\text { Sum of } \\
\text { squares }\end{array}$ & D.F. & $\begin{array}{l}\text { Mean } \\
\text { square }\end{array}$ \\
\hline \multicolumn{4}{|l|}{ Between slopes: } \\
\hline Between days & $14 \cdot 753$ & 13 & $1 \cdot 135$ \\
\hline $\begin{array}{l}\text { Between different vaccines } \\
\text { on same day }\end{array}$ & $23 \cdot 279$ & 27 & $0 \cdot 862$ \\
\hline Residual within tests & $36 \cdot 905$ & 41 & 0.900 \\
\hline
\end{tabular}

The expected value of the mean squares in Table 10 is unity, on the assumption that response is linearly related to the logarithm of the dose and that the animals form a homogeneous group in their response to the antigen. The mean squares are very close to their expected values and there is no significant departure from the values expected.

The error when a constant slope is used for interpretation. The data are consistent with the hypothesis that the true slope is constant with a value close to $0 \cdot 8$. The actual value is $0 \cdot 79 \pm 0.06$. This may be compared with Kendrick's value of $1 \cdot 46 \pm 0 \cdot 09$. These tests give a decidedly flatter slope than Kendrick's, which means that the variability of response in the mice used here was considerably greater than in Kendrick's tests. The error of the test is consequently larger.

The average value of the sum of the weights $\Sigma n u^{\prime}$ is $20 \cdot 1$; in Kendrick's tests it was $19 \cdot 6$, so that for practical purposes, the two averages are identical. These values can be used to determine the average errors of a single determination with forty-five animals and of the potency ratio of a test vaccine to a reference vaccine with forty-five animals on each preparation. For a single determination these 
errors depend, although only slightly, on the values of $5-\bar{y}$, the deviation of the average probit response from 5 ; for the determination of a potency ratio they depend slightly on $\bar{y}_{2}-\bar{y}_{1}$, the difference between the mean-probit responses to the test and reference vaccine. The results which agree with the average values found on p. 64, are shown in Table 11 .

Table 11. Average fiducial limits of error for tests with 45 animals based on the pooled slope and the average value of $\Sigma n w$, series $B$

\begin{tabular}{|c|c|c|c|c|}
\hline \multirow[b]{2}{*}{$\begin{array}{l}5-\bar{y} \text { or } \\
\bar{y}_{2}-\bar{y}_{1}\end{array}$} & \multicolumn{2}{|c|}{$\begin{array}{l}\text { Single determination } \\
\text { on the } \operatorname{ImD} 50\end{array}$} & \multicolumn{2}{|c|}{$\begin{array}{l}\text { Potency ratio-test } \\
\text { against standard }\end{array}$} \\
\hline & $\begin{array}{c}P=0.95 \\
(\%)\end{array}$ & $\begin{array}{c}P=0 \cdot 99 \\
(\%)\end{array}$ & $\begin{array}{c}P=0.95 \\
(\%)\end{array}$ & $\begin{array}{c}P=0.99 \\
(\%)\end{array}$ \\
\hline 0 & $27-364$ & $16-547$ & $16-623$ & $9-1106$ \\
\hline $0 \cdot 25$ & $27-367$ & $18-551$ & $16-628$ & $9-1118$ \\
\hline 0.50 & $27-372$ & $18-563$ & $16-641$ & $9-1150$ \\
\hline $0 \cdot 75$ & $26-382$ & $17-582$ & $15-665$ & $8-1206$ \\
\hline 1.00 & 25-395 & $16-608$ & $14-698$ & $8-1291$ \\
\hline
\end{tabular}

The different vaccines compared. Table 12 shows the ratio of the ImD 50 of each vaccine to that of $\mathrm{V} 3$ for determinations made on the same day. A weighted mean has been determined for each vaccine with the results shown in Table 13.

Table 12. Ratio of ImD 50's to corresponding ImD 50 of $\mathrm{V} 3$ in series $B$

\begin{tabular}{|c|c|c|c|c|c|c|c|}
\hline $\begin{array}{c}\text { Date } \\
\text { of experiment }\end{array}$ & V 3 & V1 & $\mathrm{V}_{2}$ & $\mathrm{Y} 2$ & NIH 4 & WRL & V4 \\
\hline 30. vii. 48 & 1.00 & 0.38 & $1 \cdot 89$ & - & - & - & - \\
\hline 6. viii. 48 & 1.00 & $37 \cdot 4$ & 152 & - & - & - & - \\
\hline 16. viii. 48 & 1.00 & - & - & 0.13 & - & - & $0 \cdot 32$ \\
\hline 17. viii. 48 & 1.00 & - & - & $1 \cdot 29$ & - & - & 0.47 \\
\hline 23. viii. 48 & $1 \cdot 00$ & $11 \cdot 2$ & $30 \cdot 4$ & - & $\ldots$ & - & - \\
\hline 24. viii. 48 & 1.00 & $\ldots$ & $15 \cdot 7$ & $1 \cdot 81$ & - & - & $\ldots$ \\
\hline 30. viii. 48 & 1.00 & - & $25 \cdot 5$ & 0.67 & - & - & - \\
\hline 31. viii. 48 & 1.00 & - & - & 1.89 & 2.59 & - & - \\
\hline 6. ix. 48 & 1.00 & - & - & 0.18 & $0 \cdot 87$ & - & - \\
\hline 7. ix. 48 & 1.00 & - & - & - & $0 \cdot 30$ & $1 \cdot 03$ & - \\
\hline 13. ix. 48 & 1.00 & - & 一 & - & $4 \cdot 73$ & 4.75 & - \\
\hline 14. ix. 48 & 1.00 & - & - & - & - & $2 \cdot 77$ & 0.26 \\
\hline 20. ix. 48 & 1.00 & - & - & - & - & $1 \cdot 10$ & 0.22 \\
\hline 21. ix. 48 & 1.00 & 0.81 & - & -- & - & - & $0 \cdot 14$ \\
\hline 27 .ix. 48 & 1.00 & $23 \cdot 9$ & - & - & - & - & $1 \cdot 14$ \\
\hline
\end{tabular}

Table 13. Average ratios of $\operatorname{ImD50}$ 's-series $B$

$\begin{array}{lcc}\text { Vaccine } & \text { ImD 50 } & \begin{array}{c}\text { Fiducial limits } \\ (P=0.95)(\%)\end{array} \\ \text { V2 } & \text { ImD 50 of V3 } & 39-256 \\ \text { V1 } & 19.6 & 38-266 \\ \text { WRL } & 6.05 & 48-208 \\ \text { NIH4 } & 2.05 & 42-238 \\ \text { V3 } & 1.34 & - \\ \text { Y2 } & 1.00 & 50-200 \\ \text { V4 } & 0.62 & 48-208\end{array}$


The ratio of the $\operatorname{ImD} 50$ of $\mathrm{V} 2$ to that of $\mathrm{V} 1$ is 3.2 with fiducial limits $P=0.95$ of $31-326 \%$. Thus V 2 is less potent than V1 (just significantly), and these two are decidedly less potent than V3. The American Standard (NIH) and vaccine WRL may be a little less potent than V 3 , but the difference is not significant for the former and only just so for the latter. V4 is definitely more potent than V 3 and Y 2 may also be, but in this case the difference is not statistically significant.

\section{(b) The determination of the LD 50}

One determination was made on each day on which tests of the vaccine were carried out. There were four doses at 10-fold intervals in each determination with fifteen mice on each dose. The values of the LD 50 were estimated by finding the best-fitting straight line connecting the probit corresponding to the mortality observed with the logarithm of the dose. Fiducial limits corresponding to $P=\mathbf{0 . 9 5}$ and 0.99 were then obtained. The statistical method used was, in fact, the same as that for the values of the ImD 50 .

There were no significant differences in slope from experiment to experiment. The results could therefore be interpreted with regard to a pooled slope. This average slope was 0.79 with a standard error of 0.06 ; this may be compared with Kendrick's values of 1.10 with a standard error of 0.11 . The difference is significant and the average slope is lower in the present series of experiments. This was also the case with the dosage-response curves for the vaccines-a result which suggests that the mice used in the present series of tests were, in general, somewhat more heterogeneous.

Table 14 gives the results and their errors. The estimates of the LD50 by the three methods (i) Reed-Muench, (ii) interpretation as a single test, (iii) interpretation with respect to a pooled slope, do not differ greatly compared with differences due to the sampling variation of the animals. When interpreted with regard to the pooled slope the average fiducial limits $(P=0.95)$ for a single determination from sixty animals are $27-410 \%$.

The $\chi^{2}$ values show that there were no significant departures of the probit-log dose relationship from linearity.

The analysis of variance of slopes is shown in Table 15. The variance ratio indicates that there is no significant difference between the two mean squares, and neither departs significantly from its expected value of unity.

In spite of the large errors there are significant differences between the estimates of the LD 50 obtained on different days; on the average a ratio of about $7: 1$ in two determinations is just significant at the $5 \%$ level. The ratios of the challenge dose to the LD 50 are also given in Table 14, column (5). There is some tendency for the ImD50 to be higher when the ratio of the challenge dose to the LD50 is higher. This is illustrated by Table 16, where the corresponding values for the two quantities are shown for vaccine V 3 . When the ratio is below 200 the ImD 50 and $R$ are unrelated: for the values above 200 there seems to be some correlation, but the data clearly do not permit of any precise determination of the relation between the two. Proportionality, certainly, cannot be inferred. 


$$
\begin{aligned}
& \text { 苟 }
\end{aligned}
$$

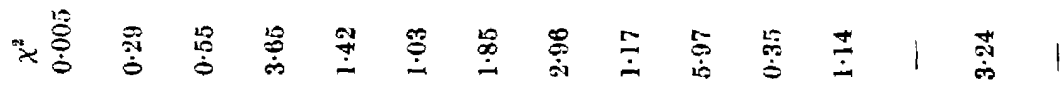

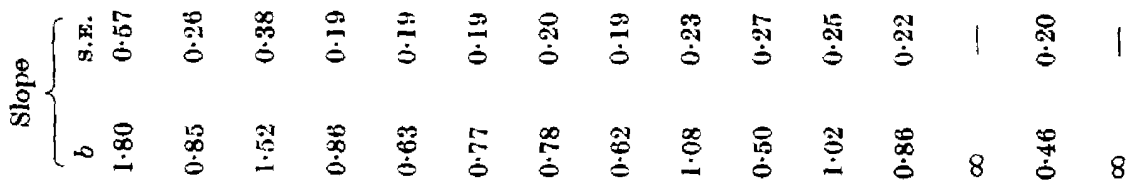

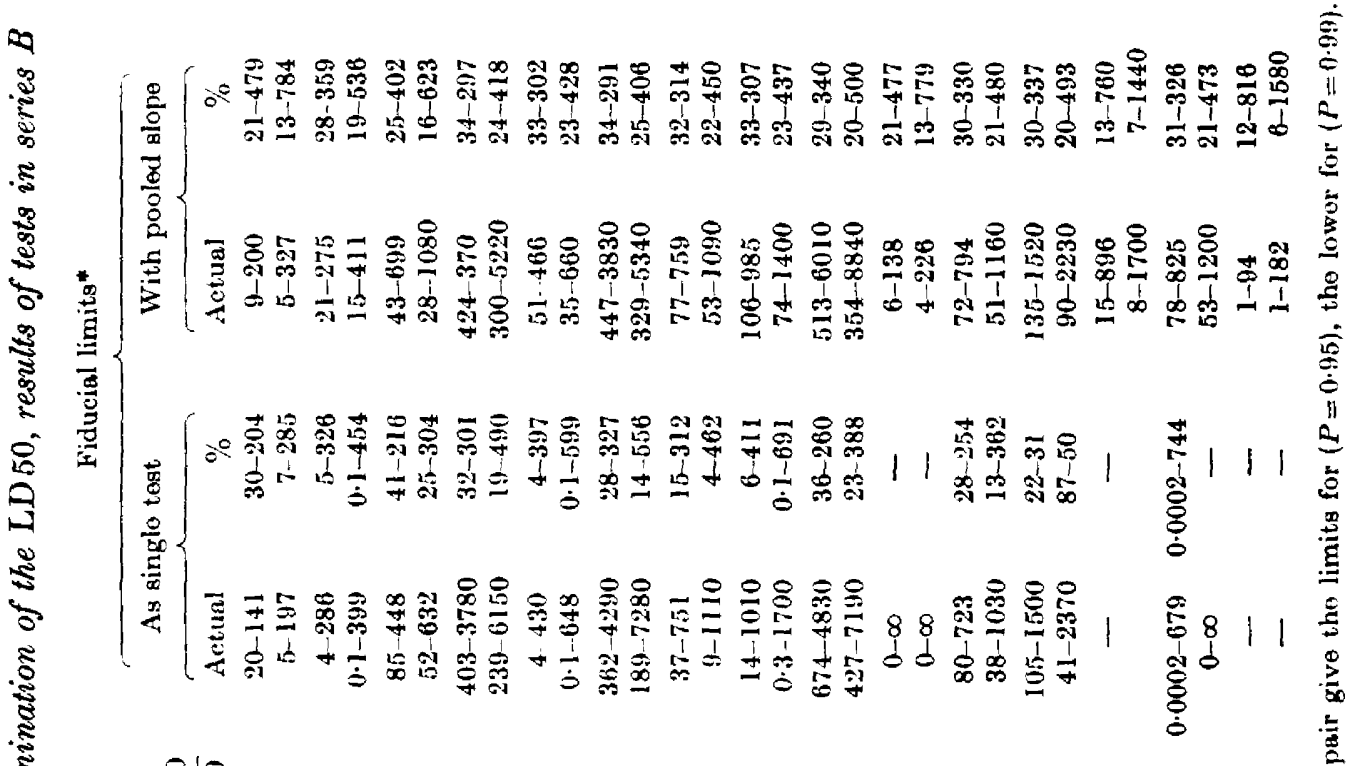

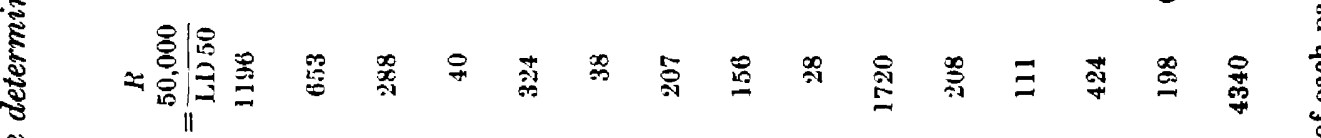

है

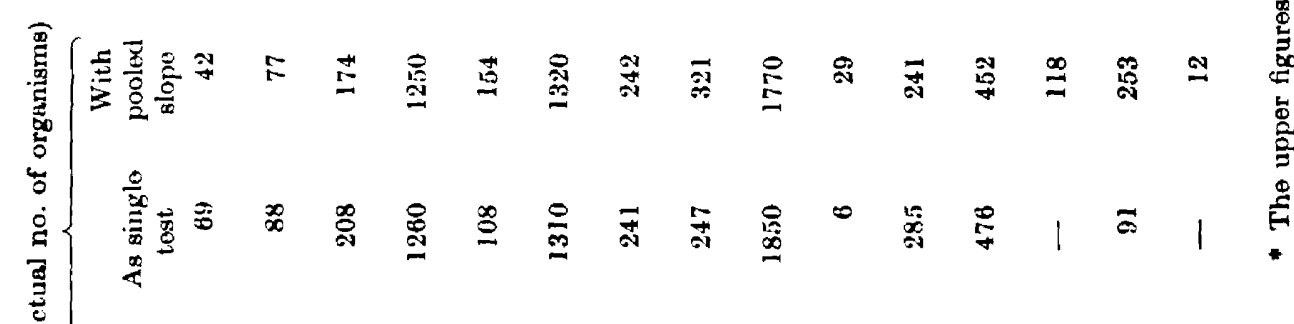

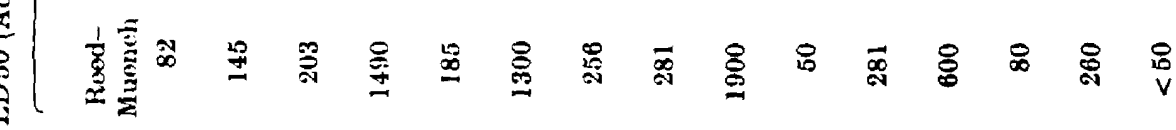

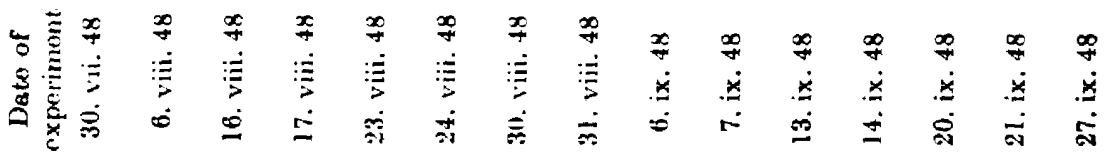


Table 15. Analysis of variance of slopes

$\left.\begin{array}{lccc} & \begin{array}{c}\text { Sum of } \\ \text { squares }\end{array} & \text { D.F. } & \text { Mean square } \\ \text { Between slopes } & 15 \cdot 005 & 12 & 1 \cdot 250 \\ \text { Residual within tests } & 23 \cdot 620 & 26 & 0 \cdot 908\end{array}\right\}$ V.R. $1 \cdot 38$

Table 16. ImD 50 of vaccine V 3 and ratio $(R)$ of challenge dose to LD 50

\begin{tabular}{crr}
$\begin{array}{c}\text { Date } \\
\text { of experiment }\end{array}$ & $\begin{array}{c}\text { ImD 50 } \\
\text { (millions) }\end{array}$ & \multicolumn{1}{c}{$R$} \\
30. vii. 48 & 26,414 & 1,196 \\
6. viii. 48 & 1,055 & 653 \\
16. viii. 48 & 1,325 & 288 \\
17. viii. 48 & 381 & 40 \\
23. viii. 48 & 386 & 324 \\
24. viii. 48 & 83 & 38 \\
30. viii. 48 & 179 & 207 \\
31. viii. 48 & 429 & 156 \\
6. ix. 48 & 520 & 28 \\
7. ix. 48 & 4,323 & 1,724 \\
13. ix. 48 & 422 & 208 \\
14. ix. 48 & 414 & 111 \\
20. ix. 48 & 7,210 & 424 \\
21. ix. 48 & 8,784 & 198 \\
27. ix. 48 & 653 & 4,344
\end{tabular}

The challenge dose was in each case 50,000 organisms.

\section{Statistical Axalysis of Series C \\ (A.F.B.S. SECOND SERIES)}

Series A and B showed that the error of a single determination of the ImD 50 with forty-five animals was large. As replication was the only practicable method of obtaining more accurate results it was determined to carry out simultaneous tests on vaccines $V 1, V 2$ and $V 3$ as far as possible twice a week for 7 weeks.

Table 17 shows the actual results obtained, numbers of survivors at dose levels of vaccine of 80,400 and $2000 \times 10^{6}$ and numbers of deaths when challenge doses of $50,000,500,50$ and 5 organisms were given.

Table 18 shows the values of the ImD 50 and of the LD 50 calculated by the Reed-Muench method. It also shows the ratio of the challenge dose to the LD 50. Where no value is given for the $\operatorname{ImD} 50$ of $\mathrm{V}_{2}$, its true value is extremely high, but no estimate could be made of it. For example, on 13 December 1948 none of the animals survived at any of the three dose levels of 80,400 and $2000 \times 10^{6}$. On 21 December 1948 the respective numbers of survivors were $2 / 15,3 / 15,0 / 15$ respectively.

There is no doubt that $\mathrm{V} 2$ is inferior to the other two vaccines. The $\operatorname{ImD} 50$ was greater in every case. $\mathrm{V} 1$ is less potent than $\mathrm{V} 3$ but not quite significantly. The ratio of ImD 50 is 1.5 with fiducial limits $0.9-2 \cdot 6$, or $60-175 \%$, at $P=0.95$. In the first series of tests the order of potency of the three vaccines was the same, but 
Table 17. Results of fourteen experiments forming series $C$

\begin{tabular}{|c|c|c|c|c|c|c|}
\hline \multirow{2}{*}{$\begin{array}{c}\text { Date of } \\
\text { experiment }\end{array}$} & \multirow{2}{*}{$\begin{array}{l}\text { Dose of } \\
\text { vaccine } \\
\text { millions }\end{array}$} & \multicolumn{3}{|c|}{ Survivors/total } & \multirow{2}{*}{$\begin{array}{c}\text { Dose of } \\
\text { challenge } \\
\text { culture }\end{array}$} & \multirow{2}{*}{$\begin{array}{c}\text { Survivors } \\
\text { total }\end{array}$} \\
\hline & & V3 & $V 1$ & $\mathrm{~V} 2$ & & \\
\hline \multirow[t]{4}{*}{ 6. xii. 48} & 80 & $\tilde{5} / 14$ & $6 / 13$ & $6 / 14$ & 50,000 & $4 / 12$ \\
\hline & 400 & $10 / 15$ & $12 / 15$ & $9 / 14$ & 500 & $6 / 13$ \\
\hline & 2,000 & $12 / 14$ & $13 / 15$ & $9 / 14$ & 50 & $10 / 14$ \\
\hline & & & & & 5 & $13 / 15$ \\
\hline \multirow[t]{4}{*}{ 7. xii. 48} & 80 & $5 / 15$ & $4 / 14$ & $1 / 13$ & 50,000 & $0 / 14$ \\
\hline & 400 & $5 / 14$ & $4 / 14$ & $1 / 10$ & 500 & $10 / 15$ \\
\hline & 2,000 & $4 / 15$ & $9 / 13$ & $2 / 11$ & 50 & $11 / 14$ \\
\hline & & & & & 5 & $9 / 14$ \\
\hline \multirow[t]{4}{*}{ 13. xii. 48} & 80 & $0 / 13$ & $0 / 15$ & $0 / 15$ & 50,000 & $0 / 16$ \\
\hline & 400 & $3 / 12$ & $2 / 14$ & $0 / 14$ & 500 & $5 / 12$ \\
\hline & 2,000 & $7 / 14$ & $10 / 11$ & $0 / 15$ & 50 & $8 / 14$ \\
\hline & & & & & 5 & $13 / 13$ \\
\hline \multirow[t]{4}{*}{ 14. xii. 48} & 80 & $5 / 14$ & $1 / 14$ & $3 / 15$ & 50,000 & $1 / 14$ \\
\hline & 400 & $9 / 15$ & $3 / 15$ & $0 / 15$ & 500 & $3 / 15$ \\
\hline & 2,000 & $7 / 15$ & $4 / 13$ & $1 / 15$ & 50 & $3 / 14$ \\
\hline & & & & & 5 & $8 / 15$ \\
\hline \multirow[t]{4}{*}{ 20. xii. 48} & 80 & $2 / 13$ & 215 & $2 / 14$ & 50,000 & $0 / 15$ \\
\hline & 400 & $8 / 14$ & $7 / 16$ & $1 / 13$ & 500 & $11 / 11$ \\
\hline & 2,000 & $9 / 15$ & $6 / 14$ & $2 / 13$ & 50 & $12 / 14$ \\
\hline & & & & & 5 & $12 / 12$ \\
\hline \multirow[t]{4}{*}{ 21. xii. 48} & 80 & $3 / 14$ & $3 / 14$ & $2 / 15$ & 50,000 & $2 / 15$ \\
\hline & 400 & $9 / 15$ & $1 / 15$ & $3 / 15$ & 500 & $11 / 13$ \\
\hline & 2,000 & $8 / 14$ & $5 / 15$ & $0 / 15$ & 50 & $11 / 13$ \\
\hline & & & & & 5 & $14 / 15$ \\
\hline \multirow[t]{4}{*}{28. xii. 48} & 80 & $1 / 14$ & $0 / 13$ & $2 / 13$ & 50,000 & $4 / 12$ \\
\hline & 400 & $6 / 13$ & $4 / 15$ & $0 / 15$ & 500 & $4 / 13$ \\
\hline & 2,000 & $8 / 12$ & $8 / 12$ & $1 / 11$ & 50 & $11 / 15$ \\
\hline & & & & & 5 & $5 / 11$ \\
\hline \multirow[t]{4}{*}{ 1. i. 49} & 80 & $2 / 11$ & $2 / 15$ & $2 / 11$ & 50,000 & $0 / 14$ \\
\hline & 400 & $5 / 10$ & $1 / 14$ & $2 / 12$ & 500 & $2 / 11$ \\
\hline & 2,000 & $7 / 12$ & $6 / 14$ & $1 / 13$ & 50 & $5 / 12$ \\
\hline & & & & & 5 & $5 / 10$ \\
\hline \multirow[t]{4}{*}{ 3. i. 49} & 80 & $3 / 14$ & $2 / 15$ & $0 / 12$ & 50,000 & $0 / 14$ \\
\hline & 400 & $9 / 15$ & $1 / 14$ & $2 / 13$ & 500 & $2 / 13$ \\
\hline & 2,000 & 9,15 & $2 / 5$ & 0,12 & 50 & $5 / 12$ \\
\hline & & & & & $\mathbf{5}$ & $2 / 6$ \\
\hline \multirow[t]{4}{*}{ 4. i. 49} & 80 & $0 / 15$ & $0 / 15$ & $1 / 13$ & 50,000 & $1 / 15$ \\
\hline & 400 & $3 / 13$ & $1 / 13$ & $2 / 14$ & 500 & $2 / 11$ \\
\hline & 2,000 & $6: 15$ & 311 & $3 / 15$ & 59 & $1 / 15$ \\
\hline & & & & & 5 & $1 / 13$ \\
\hline \multirow[t]{4}{*}{ 10. i. 49} & 80 & $1 / 13$ & $1 / 15$ & $0 / 15$ & 50,000 & $1 / 14$ \\
\hline & 400 & $1 / 15$ & $4 / 13$ & $2 / 15$ & 500 & $5 / 13$ \\
\hline & 2,000 & 915 & 614 & $0 / 15$ & 50 & $8 / 13$ \\
\hline & & & & & 5 & $12 / 14$ \\
\hline \multirow[t]{4}{*}{ 11. i. 49} & 80 & 0.15 & $1 / 15$ & 012 & 50,000 & $1 / 15$ \\
\hline & 400 & $1: 15$ & 0,14 & 213 & 500 & $4 / 12$ \\
\hline & 2,000 & $2 / 15$ & $4 / 9$ & $1 / 15$ & 50 & $9 / 15$ \\
\hline & & & & & 5 & $10 / 11$ \\
\hline 17. i. 49 & 80 & $0 / 13$ & $0 / 13$ & $1 / 11$ & 50,000 & $1 / 12$ \\
\hline & 400 & $6: 14$ & 2,13 & $0 / 15$ & 500 & $2 / 13$ \\
\hline & 2,000 & $7 / 12$ & $5 / 13$ & $0: 11$ & 50 & $2 / 15$ \\
\hline & & & & & 5 & $4 / 15$ \\
\hline 28. i. 49 & 80 & $1 / 3$ & $1 / 15$ & $1 / 14$ & 50,000 & $2 / 13$ \\
\hline & 400 & $9 / 13$ & $4 / 14$ & $3 / 13$ & 500 & $12 / 15$ \\
\hline & 2,000 & $12 / 12$ & $12 / 15$ & $0 / 14$ & 50 & $12 / 12$ \\
\hline & & & & & 5 & $12 / 13$ \\
\hline
\end{tabular}


$\mathrm{V} 1$ was significantly less potent than $\mathrm{V} 3$, with a ratio of $\operatorname{ImD} 50$ of $6 \cdot 1$ with fiducial limits $2 \cdot 3-16 \cdot 1$ or $38-266 \%$. The two fiducial ranges overlap so that the mean ratio in the two series might be the same, but the result is significantly greater in the first series of tests at the $5 \%$ level.

Table 18. Values of ImD 50 in millions and of LD50 and the ratio of LD50 to challenge dose in the fourteen experiments in series $C$

\begin{tabular}{|c|c|c|c|c|c|c|c|c|c|}
\hline \multirow{4}{*}{$\begin{array}{c}\text { Date } \\
\text { of experiment }\end{array}$} & \multicolumn{6}{|c|}{$\operatorname{ImD} 50$} & & & \\
\hline & \multicolumn{2}{|c|}{$\sqrt{13}$} & \multicolumn{2}{|c|}{$V_{1}$} & \multicolumn{2}{|c|}{$\mathrm{V} 2$} & \multirow{2}{*}{\multicolumn{2}{|c|}{ LD 50}} & \multirow{3}{*}{$R=\frac{\mathbf{5 0 , 0 0 0}}{\mathrm{LD} 50}$} \\
\hline & Value & & \multicolumn{2}{|l|}{ Value } & \multirow{2}{*}{$\begin{array}{l}\text { Value } \\
\text { millions }\end{array}$} & \multirow[b]{2}{*}{$\log$} & & & \\
\hline & millions & $\log$ & millions & $\log$ & & & Value & $\log$ & \\
\hline 6. xii. 48 & 210 & $2 \cdot 32$ & 150 & $2 \cdot 16$ & 250 & $2 \cdot 40$ & 880 & $2 \cdot 94$ & 57 \\
\hline 7. xii. 48 & 1,300 & $3 \cdot 12$ & 650 & $2 \cdot 82$ & 4,900 & 3.69 & 440 & $2 \cdot 64$ & 110 \\
\hline 13. xii. 48 & 1,400 & $3 \cdot 16$ & 850 & $2 \cdot 93$ & - & - & 260 & $2 \cdot 41$ & 190 \\
\hline 14. xii. 48 & 400 & $2 \cdot 60$ & 2,700 & $3 \cdot 43$ & 13,000 & $4 \cdot 10$ & 19 & $1 \cdot 28$ & 2,600 \\
\hline 20. xii. 48 & 510 & $2 \cdot 71$ & 900 & $2 \cdot 95$ & 5,000 & $3 \cdot 69$ & 5,000 & $3 \cdot 70$ & 10 \\
\hline 21. xii. 48 & 400 & $2 \cdot 60$ & 2,100 & $3 \cdot 32$ & $\ldots$ & - & 3,900 & $3 \cdot 59$ & 13 \\
\hline 28. xii. 48 & 630 & $2 \cdot 80$ & 950 & $2 \cdot 98$ & $\$, 800$ & $3 \cdot 95$ & 53 & $1 \cdot 72$ & 940 \\
\hline 1.i. 49 & 710 & $2 \cdot 85$ & 1,300 & $3 \cdot 10$ & - & - & 11 & $1 \cdot 04$ & 4,500 \\
\hline 3. i. 49 & 400 & $2 \cdot 60$ & 1,300 & $3 \cdot 11$ & $\cdots$ & 一 & $<5$ & - & $>10,000$ \\
\hline 4. i. 49 & 2,000 & $3 \cdot 30$ & 3,300 & $3 \cdot 52$ & 4.200 & $3 \cdot 62$ & $<\bar{s}$ & - & $>10,000$ \\
\hline 10. i. 49 & 1,300 & $3 \cdot 12$ & 1,400 & $3 \cdot 14$ & - & 一 & 170 & $2 \cdot 23$ & 300 \\
\hline 11. i. 49 & 12,000 & $4 \cdot 09$ & 2,000 & $3 \cdot 30$ & - & - & 150 & $2 \cdot 17$ & 330 \\
\hline 17. i. 49 & 830 & $2 \cdot 92$ & 2,200 & $3 \cdot 34$ &.-- & $-\cdots$ & $<\tilde{i}$ & - & $>10,000$ \\
\hline 28. i. 49 & 240 & $2-37$ & 750 & $2 \cdot 87$ & - & - & 3,500 & $3 \cdot 54$ & 14 \\
\hline
\end{tabular}

Table 19 gives the analysis of variance for the ImD 50 of vaccines $\mathrm{V} 1$ and $\mathrm{V} 3$. The average fiducial limits for a single determination of the $\operatorname{ImD} 50$ are $20-470 \%$, showing about the same accuracy as the values found in the first series of tests but somewhat less accuracy than the values found from Kendrick's data.

Table 19. Analysis of variance of $\log \mathrm{ImD50}$ 's for vaccines $\mathrm{V} 1$ and $\mathrm{V} 3$, series $C$

$\begin{array}{lcrcc} & \begin{array}{c}\text { Sum of } \\ \text { squares }\end{array} & \text { D.F. } & \begin{array}{c}\text { Mean } \\ \text { square }\end{array} & \text { Variance ratio } \\ \text { Dates } & 2 \cdot 9407 & 13 & 0 \cdot 2262 & 2 \cdot 38 \text { n.s. }(P=0.95) \\ \text { Vaccines } & 0 \cdot 2074 & 1 & 0 \cdot 2074 & 2 \cdot 18 \text { n.s. }(P=0 \cdot 95) \\ \text { Error } & 1 \cdot 2364 & 13 & 0 \cdot 0951 & \\ \quad \text { Total } & \mathbf{4 . 3 8 4 5} & & & \end{array}$

Average fiducial limits $(P=0.95)$ for a single determination $20-470 \%$.

The LD50 and their logarithms determined by the Reed-Muench method are given in Table 18. There are significant differences at different dates as judged by the average error obtained from the first series of tests. There is a suggestion of negative correlation between the $\log \operatorname{ImD} 50$ and the $\log$ LD50, but the actual values $(r=0.29$ for $\mathrm{V} 3$ and $r=0.33$ for $\mathrm{V} 1$ ) are not statistically significant on eleven observations. 


\section{Statistical Analysis of Series D \\ (Proom's tests)}

Table 20 shows the numbers of survivors at vaccine dose levels of 80,400 and $2000 \times 10^{6}$, also numbers of survivors when challenge doses of $5 \times 10^{n}(n=4,3,2,1)$ of the culture were given, in a series of tests carried out by $\mathrm{Mr} \mathrm{H}$. Proom, Wellcome Research Laboratories (Biological Division).

Table 20. Results of fourteen experiments forming series $D$

\begin{tabular}{|c|c|c|c|c|c|c|}
\hline \multirow{2}{*}{$\begin{array}{c}\text { Date of } \\
\text { experiment }\end{array}$} & \multirow{2}{*}{$\begin{array}{l}\text { Dose of } \\
\text { vaccine } \\
\text { millions }\end{array}$} & \multicolumn{3}{|c|}{ Survivors/total } & \multirow{2}{*}{$\begin{array}{l}\text { Dose of } \\
\text { challenge } \\
\text { culture }\end{array}$} & \multirow{2}{*}{$\begin{array}{c}\text { Survivors/ } \\
\text { total }\end{array}$} \\
\hline & & $\longdiv { 1 3 }$ & $V_{1}$ & $\overrightarrow{v_{2}}$ & & \\
\hline 28. vii. 48 & $\begin{array}{r}80 \\
400 \\
2,000\end{array}$ & $\begin{array}{r}0 / 15 \\
11 / 15 \\
14 / 15\end{array}$ & $\begin{array}{r}1 / 15 \\
2 / 15 \\
11 / 15\end{array}$ & $\begin{array}{l}0 / 15 \\
1 / 15 \\
0 / 15\end{array}$ & $\begin{array}{r}50,000 \\
5,000 \\
500 \\
50 \\
5\end{array}$ & $\begin{array}{l}0 / 5 \\
2 / 10 \\
4 / 10 \\
9 / 10\end{array}$ \\
\hline 6. viii. 48 & $\begin{array}{r}80 \\
400 \\
2,000\end{array}$ & $\begin{array}{r}1 / 15 \\
3 / 15 \\
12 / 15\end{array}$ & $\begin{array}{l}0 / 15 \\
0 / 15 \\
6 / 15\end{array}$ & $\begin{array}{l}0 / 15 \\
0 / 15 \\
0 / 15\end{array}$ & $\begin{array}{r}50,000 \\
5,000 \\
500 \\
50 \\
5\end{array}$ & $\begin{array}{r}0 / 5 \\
0 / 10 \\
0 / 10 \\
0 / 10 \\
5 / 10\end{array}$ \\
\hline 23. viii. 48 & $\begin{array}{r}80 \\
400 \\
2,000\end{array}$ & $\begin{array}{r}1 / 13 \\
4 / 13 \\
7 / 9\end{array}$ & $\begin{array}{l}0 / 15 \\
1 / 15 \\
5 / 15\end{array}$ & $\begin{array}{l}0 / 15 \\
0 / 15 \\
0 / 15\end{array}$ & $\begin{array}{r}50,000 \\
5,000 \\
500 \\
50 \\
5\end{array}$ & $\begin{array}{r}0 / 5 \\
0 / 5 \\
1 / 10 \\
5 / 10 \\
10 / 10\end{array}$ \\
\hline 13. ix. 48 & $\begin{array}{r}80 \\
400 \\
2,000\end{array}$ & $\begin{array}{l}0 / 15 \\
6 / 15 \\
9 / 15\end{array}$ & $\begin{array}{l}1 / 15 \\
1 / 15 \\
5 / 15\end{array}$ & $\begin{array}{l}0 / 15 \\
0 / 15 \\
1 / 15\end{array}$ & $\begin{array}{r}50,000 \\
5,000 \\
500 \\
50 \\
5\end{array}$ & $\begin{array}{r}0 / 5 \\
0 / 10 \\
7 / 10 \\
10 / 10 \\
-\end{array}$ \\
\hline 13. xii. 48 & $\begin{array}{r}80 \\
400 \\
2,000\end{array}$ & $\begin{array}{l}0 / 15 \\
1 / 15 \\
5 / 15\end{array}$ & $\begin{array}{l}0 / 15 \\
1 / 15 \\
1 / 15\end{array}$ & $\begin{array}{l}0 / 15 \\
0 / 15 \\
1 / 15\end{array}$ & $\begin{array}{r}5,000 \\
500 \\
50 \\
5\end{array}$ & $\begin{array}{r}0 / 5 \\
0 / 10 \\
1 / 10 \\
8 / 10\end{array}$ \\
\hline 20. xii. 48 & $\begin{array}{r}80 \\
400 \\
2,000\end{array}$ & $\begin{array}{l}2 / 15 \\
4 / 15 \\
9 / 15\end{array}$ & $\begin{array}{l}0 / 15 \\
1 / 15 \\
6 / 15\end{array}$ & $\begin{array}{l}0 / 15 \\
0 / 15 \\
0 / 15\end{array}$ & $\begin{array}{r}5,000 \\
500 \\
50 \\
5\end{array}$ & $\begin{array}{r}0 / 5 \\
6 / 10 \\
9 / 10 \\
10 / 10\end{array}$ \\
\hline 3. i. 49 & $\begin{array}{r}80 \\
400 \\
2,000\end{array}$ & $\begin{array}{l}0 / 15 \\
4 / 15 \\
9 / 15\end{array}$ & $\begin{array}{l}0 / 15 \\
0 / 15 \\
6 / 15\end{array}$ & $\begin{array}{l}0 / 15 \\
0 / 15 \\
1 / 15\end{array}$ & $\begin{array}{r}5,000 \\
500 \\
50 \\
5\end{array}$ & $\begin{array}{r}0 / 5 \\
2 / 10 \\
8 / 10 \\
10 / 10\end{array}$ \\
\hline 10. i. 49 & $\begin{array}{r}80 \\
400 \\
2,000\end{array}$ & $\begin{array}{l}0 / 15 \\
5 / 15 \\
5: 15\end{array}$ & $\begin{array}{l}0 / 15 \\
0 / 15 \\
6 / 15\end{array}$ & $\begin{array}{l}0 / 15 \\
0 / 15 \\
1 / 15\end{array}$ & $\begin{array}{r}5,000 \\
500 \\
50 \\
5\end{array}$ & $\begin{array}{r}0 / 5 \\
1 / 10 \\
9 / 10 \\
10 / 10\end{array}$ \\
\hline 17. i. 49 & $\begin{array}{r}80 \\
400 \\
2,000\end{array}$ & $\begin{array}{r}1 / 15 \\
4 / 15 \\
12 / 15\end{array}$ & $\begin{array}{l}0 / 15 \\
0 / 15 \\
6 / 15\end{array}$ & $\begin{array}{l}0 / 15 \\
0 / 15 \\
0 / 15\end{array}$ & $\begin{array}{r}5,000 \\
500 \\
50 \\
5\end{array}$ & $\begin{array}{r}0 / 5 \\
1 / 10 \\
10 / 10 \\
10 / 10\end{array}$ \\
\hline
\end{tabular}


Table 20 (cont.)

\begin{tabular}{|c|c|c|c|c|c|c|}
\hline \multirow{2}{*}{$\begin{array}{c}\text { Date of } \\
\text { experiment }\end{array}$} & \multirow{2}{*}{$\begin{array}{l}\text { Dose of } \\
\text { vaccine } \\
\text { millions }\end{array}$} & \multicolumn{3}{|c|}{ Survivors/total } & \multirow{2}{*}{$\begin{array}{l}\text { Dose of } \\
\text { challenge } \\
\text { culture }\end{array}$} & \multirow{2}{*}{$\begin{array}{c}\text { Survivors/ } \\
\text { total }\end{array}$} \\
\hline & & V3 & $V_{1}$ & V2 & & \\
\hline 24. i. 49 & $\begin{array}{r}80 \\
400 \\
2,000\end{array}$ & $\begin{array}{r}0 / 15 \\
2 / 15 \\
13 / 15\end{array}$ & $\begin{array}{l}0 / 15 \\
1 / 15 \\
6 / 15\end{array}$ & $\begin{array}{l}0 / 15 \\
1 / 15 \\
0 / 15\end{array}$ & $\begin{array}{r}5,000 \\
500 \\
50 \\
5\end{array}$ & $\begin{array}{r}0 / 5 \\
4 / 10 \\
9 / 10 \\
10 / 10\end{array}$ \\
\hline 31. i. 49 & $\begin{array}{r}80 \\
400 \\
2,000\end{array}$ & $\begin{array}{r}2 / 15 \\
9 / 15 \\
13 / 15\end{array}$ & $\begin{array}{r}0 / 15 \\
4 / 15 \\
10 / 15\end{array}$ & $\begin{array}{l}0 / 15 \\
0 / 15 \\
4 / 15\end{array}$ & $\begin{array}{r}5,000 \\
500 \\
50 \\
5\end{array}$ & $\begin{array}{r}0 / 5 \\
5: 10 \\
9 / 10 \\
10 \\
10\end{array}$ \\
\hline 7. ii. 49 & $\begin{array}{r}80 \\
400 \\
2,000\end{array}$ & $\begin{array}{r}5 / 15 \\
8 / 15 \\
13 / 15\end{array}$ & $\begin{array}{l}1 / 15 \\
2 / 15 \\
5 / 15\end{array}$ & $\begin{array}{l}0 / 15 \\
2 / 15 \\
3 / 15\end{array}$ & $\begin{array}{r}5,000 \\
500 \\
50 \\
5\end{array}$ & $\begin{array}{r}0 / 5 \\
2 / 6 \\
910 \\
10 / 10\end{array}$ \\
\hline 14. ii. 49 & $\begin{array}{r}80 \\
400 \\
2,000\end{array}$ & $\begin{array}{r}3 / 15 \\
8 / 15 \\
12 / 15\end{array}$ & $\begin{array}{l}1 / 15 \\
3 / 15 \\
2 / 15\end{array}$ & $\begin{array}{l}0 / 15 \\
0 / 15 \\
1 / 15\end{array}$ & $\begin{array}{r}5,000 \\
500 \\
50 \\
5\end{array}$ & $\begin{array}{r}0 / 5 \\
8 / 10 \\
10 / 10 \\
10 / 10\end{array}$ \\
\hline 21. ii. 49 & $\begin{array}{r}80 \\
400 \\
2,000\end{array}$ & $\begin{array}{l}1 / 15 \\
3 / 15 \\
7 / 15\end{array}$ & $\begin{array}{l}0 / 15 \\
0 / 15 \\
3 / 15\end{array}$ & $\begin{array}{l}0 / 15 \\
1: 15 \\
0 / 15\end{array}$ & $\begin{array}{r}5,000 \\
500 \\
50 \\
5\end{array}$ & $\begin{array}{r}0 / 5 \\
5 / 10 \\
9 / 10 \\
10 / 10\end{array}$ \\
\hline
\end{tabular}

Challenge dose 28 July to 13 September 1948 inclusive was $\mathbf{5 0 . 0 0 0}$ organisms, from 13 December 1948 to 21 February 1949, 5,000 organisms.

There was no doubt that V 2 was inferior to the other two vaccines; and as not more than one animal ever survived the protection tests, there was no point in calculating an $\operatorname{ImD} 50$ for this vaccine.

Table 21 shows the values of the ImD 50 and of the LD 50 calculated by the Reed-Muench method for vaccines $\mathrm{V} 1$ and V3. V1 is less potent than V3. The ratio of the two mean values of the ImD 50 is $4 \cdot 2$ with fiducial limits $2 \cdot 7-6 \cdot 6$, or $63-157 \%$, at $P=0.95$. This result may be compared with series $\mathrm{C}$ (also fourteen in number) which gave a result of 1.5 with fiducial limits $0 \cdot 9-2 \cdot 6$, or $60-175 \%$, at $P=0.95$; also with the series B result, $6 \cdot 1$ with fiducial limits $2 \cdot 3-16 \cdot 1$, or $38-266 \%$. The value 1.5 differs significantly from the other two at the $5 \%$ level.

Table 22 gives the analysis of variance for the ImD 50's of vaccines V 1 and V 3 . The average fiducial limits for a single determination of the ImD 50 are 33-300\%. This is somewhat more accurate than in series $\mathrm{B}$ and $\mathrm{C}(27-365$ and $20-470 \%)$, but less accurate than in series A $(49-209 \%)$. The explanation is a slope intermediate between the other two. This slope may be estimated as 0.93 compared with $1 \cdot 46 \pm 0.09$ for series $A, 0 \cdot 79 \pm 0 \cdot 06$ for series $B$ and 0.73 for series $C$. We may conclude that the colonies of mice used in different laboratories differ in the variability of tolerance of the individual mice.

The LD50's and their logarithms are given in Table 21 . They differ significantly at different dates even if judged by the average error obtained from series $B$. There is no significant correlation between $\log \operatorname{ImD} 50$ and (log (challenge dose) $-\log \mathrm{LD50}\}$ as was suggested by Kendrick. 
Table 21. Values of $\mathrm{ImD} 50$ in millions and of $\mathrm{LD} 50$ and the ratio of $\mathrm{LD} 50$ to challenge dose in the fourteen experiments in series $D$

\begin{tabular}{|c|c|c|c|c|c|c|c|}
\hline \multirow{4}{*}{$\begin{array}{c}\text { Date } \\
\text { of experiment }\end{array}$} & \multicolumn{4}{|c|}{$\operatorname{ImD} 50$} & & & \multirow{4}{*}{$\begin{array}{c}R= \\
\text { challenge dose } \\
\frac{\text { LD 50 }}{\text { LD }}\end{array}$} \\
\hline & \multicolumn{2}{|c|}{ V 3} & \multicolumn{2}{|c|}{ V 1} & \multirow{2}{*}{\multicolumn{2}{|c|}{ LD 50}} & \\
\hline & Value & & Talue & & & & \\
\hline & millions & $\log$ & millions & $\log$ & Value & $\log$ & \\
\hline 28. vii. 48 & 240 & $2 \cdot 38$ & 980 & $2 \cdot 99$ & 42 & $1 \cdot 62$ & 1,200 \\
\hline 6. viii. 48 & 840 & $2 \cdot 92$ & 2,600 & $3 \cdot 42$ & 5 & 0.70 & 10,000 \\
\hline 23. viii. 48 & 730 & $2 \cdot 86$ & 2,800 & $3 \cdot 44$ & 62 & $1 \cdot 79$ & 800 \\
\hline 13. ix. 48 & 890 & $2 \cdot 95$ & 2,500 & $3 \cdot 41$ & 970 & $2 \cdot 98$ & 52 \\
\hline 13. xii. 48 & 2,800 & $3 \cdot 44$ & 61,000 & $4 \cdot 79$ & 14 & $1 \cdot 13$ & 370 \\
\hline 20. xii. 48 & 940 & $2 \cdot 97$ & 2,400 & $3 \cdot 38$ & 620 & 2.79 & 8 \\
\hline 3. i. 49 & 1,100 & $3 \cdot 04$ & 2,600 & $3 \cdot 42$ & 160 & $2 \cdot 20$ & 32 \\
\hline 10. i. 49 & 2,000 & $3 \cdot 30$ & 2,600 & $3 \cdot 42$ & 160 & $2 \cdot 20$ & 32 \\
\hline 17. i. 49 & 770 & $2 \cdot 88$ & 2,600 & $3 \cdot 42$ & 180 & $2 \cdot 25$ & 28 \\
\hline 24. i. 49 & 900 & $2 \cdot 9 \overline{5}$ & 2.400 & $3 \cdot 38$ & 290 & $2 \cdot 46$ & 17 \\
\hline 31. i. 49 & 310 & $2 \cdot 49$ & 980 & $2 \cdot 99$ & 400 & $2 \cdot 60$ & 12 \\
\hline 7. ii. 49 & 270 & $2 \cdot 44$ & 2,300 & 3.77 & 240 & $2 \cdot 38$ & 21 \\
\hline 14. ii. 49 & 360 & $2 \cdot 56$ & 6,800 & $3 \cdot 83$ & 1200 & $3 \cdot 07$ & 4 \\
\hline 21. ii. 49 & 1,500 & 3.17 & 6,700 & $3 \cdot 83$ & 400 & $2 \cdot 60$ & 12 \\
\hline
\end{tabular}

Table 22. Analysis of variance of $\log \operatorname{ImD} 50$ 's for vaccines $\mathrm{VI}$ and $\mathrm{V} 3$ from series $D$

$\begin{array}{lcrrr} & \begin{array}{c}\text { Sum of } \\ \text { squares }\end{array} & \text { D.F. } & \begin{array}{c}\text { Mean } \\ \text { square }\end{array} & \begin{array}{c}\text { Variance } \\ \text { ratio }\end{array} \\ \text { Dates } & 3.035 & 13 & 0.233 & 4.0 \text { sign. } \\ \text { Vaccines } & 2 \cdot 713 & 1 & 2.713 & 46.8 \text { sign. } \\ \text { Error } & 0.761 & 13 & 0.058 & \\ & 6.509 & 27 & & \end{array}$

Average fiducial limits for a single determination $(30-330 \%)$.

\section{RECOMMENDATIONS FOR ROUTINE TESTING}

The routine testing of pertussis vaccine for potency, in terms of the British Standard for Pertussis Vaccine, will be recommended in the report of the Medical Research Council's Trial (1956). The British Standard, itself, will be described in a separate communication by Armitage \& Perry (1957).

The actual legal requirements for batches of vaccine to be used in children is a matter for Regulations made under the Therapeutic Substances Act; and similar requirements may be included in the monograph on Pertussis Vaccine of the British Pharmacopoeia.

Whatever the final requirements may be (and they will take into account the effect, in children, of the Standard itself as well as the practical difficulties of the assay) they will probably take some such form as the following: 'The estimated potency of the vaccine under test should be at least $x \%$ of that of the standard and the lower fiducial limit $(P=0.95)$ should be at least $y \%$ of the estimated potency. Here, for example, $x$ might be 200 and $y$ might be 50.' 
If the manufacturer can, on the average, produce a vaccine $k$ times as potent as the standard, he can estimate how many tests he need carry out to satisfy the specification, with reasonable certainty. If $k=4$, for instance, with $x=200, y=50$ about five tests would be necessary to satisfy the specification. This assumes a slope of $b=1.0$ which, on existing information, seems a fair estimate. If a slope of 1.5 were regularly obtained the number of tests needed would fall to about three, and it should be possible to use a $2 \times 2$ assay with twenty mice per dose for routine purposes (W. L. M. Perry, 1955, private communication).

The results for individual assays can be worked out by the method suggested in Appendix XV of the British Pharmacopoeia, 1953. The method given there for pooling the results of a number of assays might often be inapplicable for pertussis vaccine because the quantity ' $g$ '* exceeded $0 \cdot 1$. This difficulty can be overcome by calculating a pooled slope from the set of five assays and reinterpreting each assay with regard to the pooled slope. The modified results so obtained can then be pooled by calculating their weighted mean in the manner described in Appendix XV. The weights would now be the reciprocals of the sampling variances of the estimates obtained by using a pooled slope.

\section{Example}

(1) An assay is carried out with twenty animals per dose and two doses of each of the standard and test preparations. The two doses of the test preparation are $50 \times 10^{6}$ and $500 \times 10^{8}$ and of the standard $200 \times 10^{6}$ and $2000 \times 10^{6}$. The numbers of survivors are $6 / 20$ and $12 / 20$ for the standard preparation and 5/20,14/20 for the test preparation.

These figures are the same as in Example VI of Appendix XV, but the dose interval is now 10 -fold, so that

$$
\begin{gathered}
I=\log 10=1 \text { and } b=0.98 / I=0.98, \\
M=0.06 / b=0.0612 . \quad \text { Potency ratio }=1 \cdot 15 .
\end{gathered}
$$

The actual potency will be 4 times this or $4 \cdot 60$ times that of the standard.

We now have

$\log$ fiducial limits per cent

$$
A=0 \cdot 0865, \quad B=\frac{0.0865}{I}=0 \cdot 0865, \quad g=\frac{0 \cdot 0865(3 \cdot 84)}{(0.98)^{2}}=0 \cdot 346,
$$

$$
\begin{aligned}
& =2+\frac{(0.346)(0.0612)}{0.654} \pm \frac{1.96}{(0.98)} \frac{(0.654)}{\{(0.0865)(0.654)+(0.0865)(0.00375)\}} \\
& =2+\frac{(0 \cdot 0212)}{0 \cdot 654} \pm \frac{1 \cdot 96}{0 \cdot 6409} \sqrt{ }\{0 \cdot 0566+0 \cdot 0003\} \\
& =2 \cdot 0324 \pm 3 \cdot 058 \sqrt{ }(0.0569) \\
& =2 \cdot 0324 \pm 3 \cdot 058(0 \cdot 2385) \\
& =2.0324 \pm 0.7293 \\
& =1.3031 \text { to } 2.7617 \text {. }
\end{aligned}
$$

Fiducial limits of error $=20-578 \%$.

* $g=t^{2} V(b) / b^{2}$, where $b$ is the slope and $V(b)$ is its variance, for quantal assays $t=1.96$. 
(2) Suppose this test and four similar tests gave the following values for $b$ and $B$ :

$\begin{array}{cccc} & b & B & W_{b}=1 / B \\ (1) & 0.98 & 0.0865 & 11.56 \\ (2) & 1.26 & 0.0829 & 12.06 \\ (3) & 1.02 & 0.0850 & 11.76 \\ (4) & 0.82 & 0.0875 & 11.43 \\ (5) & 0.88 & 0.0835 & 11.98\end{array}$

The weighted mean is $\quad \frac{\Sigma W_{b} b}{\Sigma W_{b}}=\frac{5843 \cdot 46}{58 \cdot 79}=0.994$.

With standard error

$$
\sqrt{ }\left(1 / W_{\bar{b}}\right)=0 \cdot 130 \text {. }
$$

We now have

$$
V(\bar{b})=1 / \Sigma W_{b}=0.0170, \quad g=t^{2} V(\bar{b}) / \bar{b}^{2}=\frac{(0.0170)(3 \cdot 84)}{0.988}=0.066 .
$$

Thus we are justified in taking the result for any one of the assays as $M=F / \bar{b}$ with a standard error

$$
s_{M}=\frac{1}{\bar{b}} \sqrt{ }\left\{A+M^{2} V(\bar{b})\right\} .
$$

The log limits per cent for any one assay are now

$$
2 \pm \frac{t}{\bar{b}} \sqrt{ }\left\{A+M^{2} V(\bar{b})\right\}
$$

In particular, the modified result for the first assay is now

$$
M=\frac{0.06}{0.994}=0.0604 \text { and potency ratio }=1 \cdot 15
$$

as before, but the log limits per cent are now:

$$
\begin{aligned}
2 \pm \frac{1.96}{0.994} \sqrt{ }\{0.0865 & +0.00368(0.0170)\} \\
& =2 \pm 1.972 \sqrt{ }\{0.0865+0.0001\} \\
& =2 \pm 1.972 \sqrt{ }\{0.0866\} \\
& =2 \pm 1.972(0.294) \\
& =2 \pm 0.583 \\
& =1.420 \text { to } 2.580 .
\end{aligned}
$$

Limits of error are $26-380 \%$.

When the individual assays have been interpreted with regard to the pooled slope, a weighted mean of the five results may be obtained in the manner described in Appendix XV, p. 790.

The variance of a single estimate of $M$ is $\left(A+M^{2} V(\bar{b})\right) / \bar{b}^{2}$ and the appropriate $(W)$ is $1 / V(M)$. Thus

$$
\begin{gathered}
\bar{M}=\frac{\Sigma(W M)}{\Sigma W}, \\
V(\bar{M})=\text { variance of } \bar{M}=\frac{1}{\Sigma W} .
\end{gathered}
$$

The fiducial limits of error for $\bar{M}$ are $\bar{M} \pm t \sqrt{ }\{V(M)\}$, where $t=1 \cdot 96$ at the $5 \%$ level. 
In this example a 10-fold dose ratio was employed, so as to give a slope in accordance with pertussis experience, while at the same time retaining the same responses as in the example in Appendix XV of the British Pharmacopoeia. In practice it might be more advantageous to use some other dose ratio; say a 5-fold dose ratio with doses of $80 \times 10^{6}, 400 \times 10^{6}$ on the test vaccine and $320 \times 10^{6}$, $1600 \times 10^{6}$ on the standard, if the test vaccine was in fact expected to be 4 times as strong as the standard.

When groups of tests are carried out as a matter of routine, it would be worth while to keep a control chart for the values of $\vec{b}$.

When say six sets of five tests have been carried out, the weighted mean of the six values of $\bar{b}$, say $\hat{b}$, is obtained and its position marked by a horizontal line on the chart. The average variance of $\bar{b}$ is obtained; it is given by $6 / \Sigma W_{\vec{b}}$, the summation being over all the six sets. The standard error of $\bar{b}, s_{\bar{b}}$, is the square root of this; the standard error of $\hat{b}$ is $1 / \Sigma W_{\bar{b}}$. Inner and outer control limits can now be marked on the chart by horizontal lines. The inner control limits can be taken at $\hat{b}+1.96 s_{\bar{b}}$ and the outer at $\hat{b} \pm 2.58 s_{\bar{b}}$. The values of $\bar{b}$ can now be plotted on the chart, as they are obtained. As long as the true slope remains unchanged there is a probability of 0.95 that a point lies between the inner control limits, and a probability of 0.025 that it falls above the upper of the two inner limits with an equal probability of 0.025 that if falls below the lower. For the outer control limits the corresponding probabilities are 0.99 and 0.005 . If a point falls outside the inner limits this can be taken as a signal that the situation needs watching; if it falls beyond the outer limits it can be taken as an indication that the slope is changing or is not 'under control'.

If the slope is under control the value of $\hat{b}$ can be used with its appropriate weight or sampling variance in calculating the result of any assay, with a consequent gain in precision. From time to time, always assuming the slope remains under control, the value of $\hat{b}$ can be revised by including the results of new tests with those of the old. This will produce a further gain in precision.

\section{SCMMARY AND CONCLCSIONS}

Four series of tests, A, B, C and D, have been considered in detail. In the first two series, to obtain the values of the $\operatorname{ImD} 50$, percentages of survivors were transformed into probits, and the best-fitting straight lines connecting the probits with the logarithms of the doses were obtained by the method of maximum likelihood. This is the most accurate method to use. These results showed that the error of the test was large, but there were no significant differences in the slope of the probit$\log$ dose relation in the results of tests from any one laboratory. The slope $(1 \cdot 46 \pm 0 \cdot 09)$ obtained from series $A$ was greater than that from series $B(0 \cdot 79 \pm 0 \cdot 06)$. with a consequent increase in accuracy.

It was clear from the first two series that many mice would be needed to detect significant differences in potency between vaccines; in series $\mathrm{C}$, therefore, repeated tests on three vaccines were carried out-twice a week for 7 weeks. Later, in series $D$, fourteen further replicate tests on the same vaccines were carried out. The 
values of the $\operatorname{ImD} 50$ in both these series were calculated by the Reed-Muench* (1938) method, and the error and slope were estimated from an analysis of variance of the results. The estimates of slope were 0.73 for series $C$ and 0.93 for series $D$.

Table 23 shows for each of series A, B, C, D the average fiducial limits of error $(P=0.95)$ for a single determination of the $\operatorname{ImD} 50$ from forty-five animals (three doses) and for a determination of the relative potency of two vaccines using, in all, ninety animals. These tables also show the average slopes obtained. The results from series $\mathrm{C}$ agree closely with those from series $\mathrm{B}$. The agreement is even closer than Table 23 suggests; the increase in the second series is due to the method of estimation adopted (only 13 D.F. were available for error) and not to an increase in the average logarithmic standard error. The accuracy of series $\mathrm{D}$ is intermediate between that of $\mathrm{A}$ and $\mathrm{B}$ or $\mathrm{C}$.

Table 23. Average fiducial limits per cent $(P=0.95)$ and slope in the four series of tests

\begin{tabular}{ccccc} 
Single $\operatorname{ImD} 50$ & $\begin{array}{c}\text { Potency ratio } \\
\text { of two vaccines }\end{array}$ & \multicolumn{2}{c}{ Slope and s.e. } \\
$49-209$ & $35-283$ & 1.46 & 0.09 \\
$27-365$ & $16-624$ & 0.79 & 0.06 \\
$20-470$ & $11-891$ & 0.73 & - \\
$33-300$ & $21-473$ & 0.93 & -
\end{tabular}

On the basis of series $\mathrm{B}$ or $\mathrm{C}$ we may take the average fiducial limits for an ImD 50 obtained from forty-five animals to be $25-400 \%$, on the basis of series D $33-300 \%$. For a slope of $1 \cdot 4$ the corresponding result is approximately $50-200 \%$.

Tables 24 and 25 show (i) on the basis of series B or C and (ii) on the basis of series $\mathrm{D}$, the fiducial limits $(P=0.95)$ for tests with given numbers of mice. If the slope is 1.4 Table 24 will be approximately correct, if the number of mice in each row of the table is divided by 4 .

Table 24 shows for example, that in a comparison between two vaccines, the result obtained would not with any certainty indicate a difference between them, when 180 animals in all are used (not counting those used to determine the LD 50 of the culture), unless the estimated potency ratio is $>4$ or $<\frac{1}{4}$. The corresponding figures from Table 25 are $>3$ or $<\frac{1}{3}$.

The standard tests employ 150 mice of which ninety are used in the comparison of the two vaccines and sixty for the titration of the challenge dose. Using the slope $0 \cdot 79$ obtained from series $B$, it may be calculated that, on the average, eight tests are needed (and series $C$ supports this) to enable one to assert a significant

* A number of other approximate methods of estimating median effective doses have been given. Armitage \& Allen (1950) and Finney (1952) have discussed their accuracy. Errors of estimation by most of these methods, including of course the Reed-Muench, are usually small compared with the sampling variation of the animals. 
Table 24. Average fiducial limits of error $(P=0.95)$ for tests with varying numbers of mice. Based on series $B$

(It is assumed that the limits for a single determination of the ImD 50 with forty-five animals are $25-400 \%$ )

$\begin{array}{cc}\begin{array}{c}\text { Total no. } \\ \text { of mice }\end{array} & 1.96 \sigma^{*} \\ 10 & 1 \cdot 2792 \\ 20 & 0.9045 \\ 40 & 0.6396 \\ 45 & 0.6021 \\ 50 & 0.5720 \\ 90 & 0.4258 \\ 100 & 0.4039 \\ 135 & 0.3665 \\ 200 & 0.2956 \\ 360 & 0.2126\end{array}$

Fiducial
limits $(\%)$
$5 \cdot 3-1900$
$12-800$
$23-430$
$25-400$
$27-370$
$38-270$
$39-250$
$43-235$
$52-190$
$61-160$

$\begin{array}{ccc}\begin{array}{c}\text { Total no. } \\ \text { of mice }\end{array} & 1 \cdot 96 \sigma^{*} & \begin{array}{c}\text { Fiducial } \\ \text { limits }(\%)\end{array} \\ 20 & 1 \cdot 8089 & 1 \cdot 7-6400 \\ 40 & 1 \cdot 2792 & 5 \cdot 3-1900 \\ 80 & 0 \cdot 9045 & 12-800 \\ 90 & 0 \cdot 8515 & 14-700 \\ 100 & 0 \cdot 8089 & 16-640 \\ 180 & 0 \cdot 6030 & 25-400 \\ 200 & 0 \cdot 5720 & 27-370 \\ 270 & 0 \cdot 4923 & 32-320 \\ 400 & 0 \cdot 4039 & 39-250 \\ 720 & 0 \cdot 3010 & 50-200\end{array}$

* $\sigma=$ standard error of logarithm of result.

Table 25. Average fiducial limits of error $(P=0 \cdot 95)$ for tests with varying numbers of mice. Based on series $D$

(It is assumed that the limits for a single determination of the $\operatorname{ImD} 50$ with forty-five animals are $33-300 \%$ )

Single determination of the $\operatorname{ImD} 50$

Total no
of mice
10
20
40
45
50
90
100
135
200
360

$\begin{array}{lc}1.96 \sigma^{*} & \text { Fiducial } \\ 1.0057 & 10-1000 \\ 0.7112 & 19-510 \\ 0.5029 & 32-310 \\ 0.4741 & 33-300 \\ 0 \cdot 4498 & 35-280 \\ 0.3352 & 46-220 \\ 0.3180 & 48-210 \\ 0.2737 & 53-190 \\ 0.2249 & 60-170 \\ 0.1676 & 68-150\end{array}$

* $\sigma=$ standard error of logarithm of result.

$\begin{array}{ccc}\begin{array}{c}\text { Total no. } \\ \text { of mice }\end{array} & 1.96 \sigma^{*} & \begin{array}{c}\text { Fiducial } \\ \text { limits } \%\end{array} \\ 20 & 1.4221 & 37-2700 \\ 40 & 1.0057 & 10-1000 \\ 80 & 0.7112 & 19-510 \\ 90 & 0.6705 & 21-470 \\ 100 & 0.6361 & 23-430 \\ 180 & 0.4741 & 33-300 \\ 200 & 0.4498 & 35-280 \\ 270 & 0.3871 & 41-240 \\ 400 & 0.3180 & 48-210 \\ 720 & 0.2371 & 58-170\end{array}$

difference (at the $5 \%$ level) when the estimated potency is greater than 2 or less than $\frac{1}{2}$. For a slope of 1.46 (series A) the corresponding number of tests necessary is 2 ; for a slope of 0.93 (series $D$ ) it is 5 .

Later tests (unpublished) gave slopes from $0 \cdot 99 \pm 0 \cdot 13$ to $1 \cdot 42 \pm 0 \cdot 13$, and it may therefore well be that the slopes obtained in the earlier series of assays are underestimating the accuracy now obtainable.

Tables 24 and 25 tell us, for a given number of animals, under what circumstances we can detect any difference at all. There is, however, another question which may need answering. If one vaccine is in fact 4 times as potent as the other, what is the least number of animals needed in order that the chance of failing to get a 
significant result in the test will be 0.05 ? The number of animals may be obtained as follows. We look in the last column of Table 24 or Table 25 for limits of $25-400 \%$. We take the corresponding number of animals from the fourth column and multiply by $3 \cdot 4$. i.e. $(1 \cdot 96+1 \cdot 64)^{2} /(1 \cdot 96)^{2}$. The figure obtained is 612 or about 600 . Table 25 gives about 400 . Other particular cases may be similarly treated. Table 26 gives some further information.

Table 26. Number of tests necessary in order to be 'reasonably sure' that a real difference is not missed

\begin{tabular}{cccc} 
True ratio & \multicolumn{4}{c}{$\begin{array}{c}\text { Slope } \\
\text { No. of tests } \\
2: 1\end{array}$} & $28 \cdot 93$ & 18 & 7 \\
$3: 1$ & 12 & 7 & 3 \\
$4: 1$ & 7 & 5 & 2 \\
$5: 1$ & 6 & 3 & 1
\end{tabular}

\footnotetext{
'Reasonably sure' here means that the chance of failing to detect the difference, when the usual significance test is used, is $\mathbf{0 . 0 5}$. The number of tests necessary depends on the true ratio and on the slope ' $b$ ' of the probit-log dose response curve.
}

In an attempt to reduce the number of mice required a series of assays were carried out, subsequent to the series $A-D$, in which litter mates were used, one member of each litter being placed on each dose. The procedure did not, however, result in any appreciable increase of accuracy, commensurate with the large amount of work involved (Irwin \& Standfast, 1955).

In spite of the large numbers of animals necessary, significant differences between various vaccines have been found. For instance, series $B, C$ and $D$ all agreed in showing that of the three vaccines $\mathrm{V} 1, \mathrm{~V} 2$ and $\mathrm{V} 3$ used in the pertussis field trials V2 was much less potent than the other two and V1 less potent than $\mathrm{V} 3$ as judged by trials on mice.

The LD50's of the cultures have been examined in detail. There were sometimes significant differences in tests carried out at different times, but no significant changes of slope in the same laboratory. It was not possible from the data examined to establish any precise relation between the $\operatorname{ImD} 50$ of a vaccine and the ratio of the challenge dose to the LD 50 .

Recommendations for routine testing have been made. The requirements for batches of pertussis vaccine to be used in children is a matter for Regulations made under the Therapeutic Substances Act. Whatever these may be they must be in terms of a reference vaccine such as the British Standard for Pertussis Vaccine and will probably take such a form as: "the estimated potency of the vaccine should be at least $x \%$ of that of the standard and the lower fiducial limit should be at least $y \%$ of the estimated potency.' When these standards are known, then the manufacturer can estimate with reasonable certainty the number of tests, and so the number of mice, he will require for a complete assay as he will know the level of accuracy obtained in his own testing laboratories, and will probably have some idea of the customary or expected potency of his unknown vaccine. 
This work was done under the auspices of the M.R.C. Whooping Cough Immunization Committee. We must acknowledge our indebtedness to Dr P. Armitage for many helpful discussions and to Miss Irene Allen for the great amount of arithmetical work which she carried out.

\section{REFERENCES}

Armitage, P. \& Allex, I. (1950). Methods of estimating the LD50 in quantal response data. J. Hyg.. Camb., 48, 298.

Armitage, P. \& Perry, W. L. M. (1957). The British Standard for pertussis vaccine. To be published.

FinNey, D. J. (1952). Statistical Method in Biological Assay, chapter 20. London: Griffin.

Irwin, J. O. \& Standfast, A. F. B. (1955). Litter-mate assays of pert ussis vaccine. J. Hyg., Camb., 53, 106.

Kendrick, P. L., Eldering, G., Dixon, M. K. \& Misner, J. (1947). Mouse protection tests in the study of pertussis vaccine. Amer. J. publ. Hlth, 37, 803.

Kendrick, P. L., Updyke, E. L. \& Eldering, G. (1949). Comparison of pertussis cultures by mouse protection and virulence tests. Amer. J. publ. Hlth, 39, 179.

Litchfield, J. T. \& Fertig, J. W. (1941). On a graphical solution of the dosage-effect curve. Johns Hopk. Hosp. Bull. 69, 276.

Medical Research Coevcil (1956). Report on vaccination against whooping cough. Brit. med. J. 2, 454.

Minimal Requirements (1948). Pertussis Vaccine. National Institutes of Health, Bethesda, Md., U.S.A.

REeD, L. J. \& M Amer. J. Hyg. 27, 493.

Worcester, J. \& Wilson, E. B. (1943). A table for determining LD 50 or the fifty per cent endpoint. Proc, nat. Acad. Sci., Wash., 29, 207.

World Health Organization Technical Report Series (1953). Diphtheria and Pertusgis Vaccination, no. 61, p. 66.

(MS. received for publication 29. vII. 56) 